\title{
Surface-Induced Dissociation of Small Molecules, Peptides, and Non-Covalent Protein Complexes
}

\author{
Vicki H. Wysocki, Karen E. Joyce, Christopher M. Jones, and \\ Richard L. Beardsley \\ Department of Chemistry, University of Arizona, Tucson, Arizona, USA
}

This article provides a perspective on collisions of ions with surfaces, including surfaceinduced dissociation (SID) and reactive ion scattering spectrometry (RISS). The content is organized into sections on surface-induced dissociation of small ions, surface characterization of organic thin films by collision of well-characterized ions into surfaces, the use of SID to probe peptide fragmentation, and the dissociation of large non-covalent complexes by SID. Examples are given from the literature with a focus on experiments from the authors' laboratory. The article is not a comprehensive review but is designed to provide the reader with an overview of the types of results possible by collisions of ions into surfaces. (J Am Soc Mass Spectrom 2008, 19, 190-208) (C) 2008 American Society for Mass Spectrometry

$\mathrm{T}$ Tandem mass spectrometry (MS/MS) is an essential tool for elucidating ion structure. The MS/MS experiment involves mass selection of a precursor ion followed by ion activation and subsequent dissociation. The ion activation step is commonly accomplished via collision-induced dissociation (CID) in which the initial kinetic energy of a projectile ion is converted into internal energy through inelastic collisions with a neutral gas. Several alternative activation methods have been used in tandem mass spectrometry, one of which is surfaceinduced dissociation (SID). SID is analogous to CID, except that a surface replaces the neutral gas as the collision target. A typical ion-surface collision event is illustrated in Figure 1.

The incorporation of a surface into a mass spectrometer for ion activation was pioneered in the laboratory of R. Graham Cooks in the mid-1970s and early 1980s [1-3]. Since that time, collisions of lowenergy $(\mathrm{eV})$ organic ions with surfaces within the tandem mass spectrometer have been valuable for analyzing surface composition, characterizing reactions between organic projectile ions and surface adsorbates, chemically modifying surfaces, and determining projectile ion structure. A major motivation for development of SID is that energy transfer to

Address reprint requests to Dr. Vicki H. Wysocki, University of Arizona, Department of Chemistry, 1306 E. University Blvd., Box 21-0041, Tucson, AZ 85721-0041. E-mail: vwysocki@email.arizona.edu ionic projectiles can be improved by increasing the mass of the collision target. The total available energy for transfer into the internal modes of the projectile ion is defined by the center-of-mass energy $\left(\mathrm{E}_{\mathrm{COM}}\right)$ described by eq 1 :

$$
\mathrm{E}_{\mathrm{COM}}=\frac{\mathrm{M}_{\mathrm{N}}}{\mathrm{M}_{\mathrm{ION}}+\mathrm{M}_{\mathrm{N}}} \mathrm{E}_{\mathrm{LAB}}
$$

where $\mathrm{E}_{\mathrm{LAB}}$ is the laboratory collision energy and $\mathrm{M}_{\mathrm{ION}}$ and $\mathrm{M}_{\mathrm{N}}$ are the masses of the projectile ion and neutral, respectively. Energy transfer in CID is limited by the mass of the collision partner, typically inert gases such as helium, argon, or xenon. In SID, if one assumes that the surface is an infinitely large collision partner, $\mathrm{E}_{\mathrm{COM}}$ becomes independent of mass and approaches the laboratory collision energy. The assumption that the entire surface can be viewed as the collision partner is not always valid, however, and there are instances where the mass of the terminal groups on the surface influence the amount of energy transfer $[4,5]$. Nonetheless, the use of a massive surface target should, in theory, provide greater energy transfer.

Use of a surface has several other attractive features, including no gas load on the instrument, no need to reproduce a specific gas pressure, and the ability to deposit energy in one fast, large deposition step rather than "slow heating" of the ions by CID (slow heating may lead to more rearrangement products). Figure 2 is a simple depiction of how these different types of 


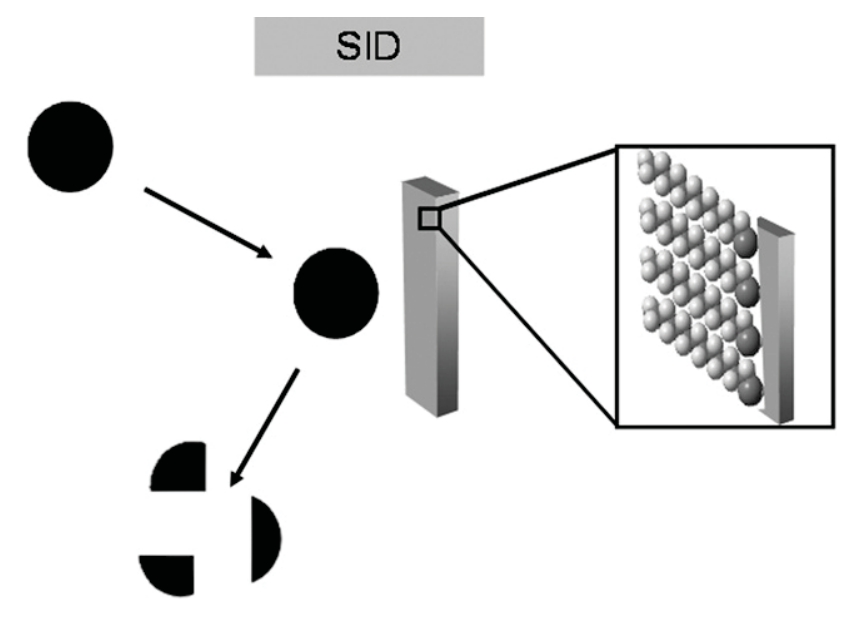

Figure 1. Diagram of surface-induced dissociation where surface collision event deposits energy into the precursor ion. Collisions can generate fragment ions, neutralized precursor molecules, sputtered surface atoms, and ion-surface reaction products. Inset shows an all-trans configuration alkanethiolate (e.g., $\mathrm{CH}_{3}\left(\mathrm{CH}_{2}\right)_{11} \mathrm{~S}-$ $\mathrm{Au}$ ) self-assembled monolayer on gold.

activation methods may affect the observed dissociation pathways as described previously by Wysocki and Kenttamaa for ion traps versus triple quadrupoles [6] and Laskin, Denisov, and Futrell for SID versus multiplecollision CID [7]. Surface-induced dissociation has been implemented in many different instrument platforms including magnetic sector-electric sector (BE)surface-electric sector quadrupole (EQ), reflectron timeof-flight mass spectrometry (TOF MS), Q-surface-Q, TOF-surface-TOF, Q-surface-TOF, Fourier transform ion cyclotron resonance (FT-ICR), and matrix-assisted laser desorption ionization-ion mobility-surface-induced dissociation-time-of-flight (MALDI-IM-SID-TOF). Information on different types of tandem mass spectrometers used to examine SID phenomena are available in a review from 2001 [8]. Many types of surfaces have been used in these experiments including contaminated metals, graphite, diamond, Langmuir-Blodgett films, and the often-used hydrocarbon, fluorocarbon, and functionalized alkanethiolate self-assembled monolayer (SAM) films illustrated in the inset of Figure 1. Because the chemical composition of the surface has a substantial effect on the nature of the ion-surface collision, it is important to understand the extent of energy deposition, electron transfer, and reactivity of different surfaces, as well as to examine the effects of surface stiffness and roughness.

This brief perspective describes the SID activation method for fragmenting projectile ions in tandem mass spectrometry (MS/MS). It should be noted that ionsurface reactions can result in a number of chemically interesting phenomena and are not limited to surfaceinduced dissociation. Chemical sputtering, elastic and reactive ion scattering, and soft landing are all prevalent chemical processes that occur in the hyperthermal (1$100 \mathrm{eV}$ ) collision energy regime, and descriptions of each can be found in recent reviews [8, 9]. The purpose of this article is to focus on ion-surface collisions as they pertain to ion activation, offering a perspective on SID and its application to various systems of interest and to present only a brief description of reactive ion scattering spectrometry (RISS). For SID, extensive fragmentation has been accomplished for small molecules, isomeric compounds, salt crystals, fullerenes, peptides, and, recently, non-covalent protein complexes. The content presented here progresses from collisions of small ions with surfaces to collisions of large non-covalent complexes with surfaces. For some systems, CID and SID spectra look very similar; presumably the fragmentation pathways and kinetics of fragmentation control the spectral appearance such that differences in the distribution of energy deposited or the stepwise nature of energy deposition do not lead to differences in spectra. For other systems, such as the large noncovalent complexes, SID achieves fragmentation not observed by CID.

\section{Small Molecule Projectiles: SID and RISS}

With the advent of SID as an ion activation method, studies were required to probe the potential of this technique. Low $m / z$ polyatomic radical ions with simple, well-characterized fragmentation profiles were used to conduct initial experiments. Low $\mathrm{m} / \mathrm{z}$ molecular ions were also used for reactive ion scattering spectrometry experiments that allow characterization of the surface.

\section{Small Projectile Ion Fragmentation by SID}

Low $m / z$ polyatomic ions with well-known dissociation energetics were used to study the utility of ion surface collisions for the fragmentation of low $\mathrm{m} / \mathrm{z}$ molecules. Small molecules such as $\mathrm{Fe}(\mathrm{CO})_{5}$ and $\left(\mathrm{C}_{2} \mathrm{H}_{5}\right)_{4} \mathrm{Si}$ were used by Cooks and colleagues to investigate internal energy distributions deposited into projectiles upon surface collisions $[8,10,11]$. These "thermometer ions"
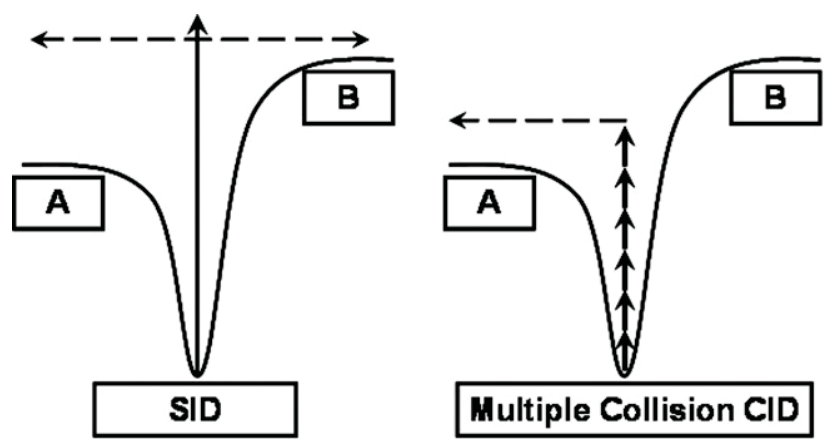

Figure 2. Reaction coordinates for SID and CID depicting sudden versus gradual activation of protein complexes. When internal energy is deposited in a single event, dissociation pathways that do not involve unfolding may be accessible [6, 7]. 


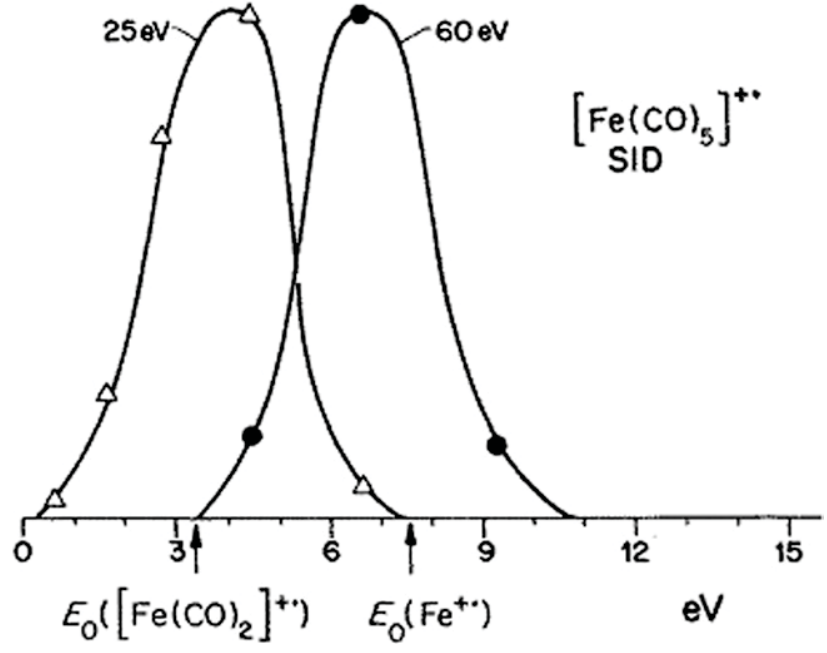

Figure 3. Internal energy distributions of $\left[\mathrm{Fe}(\mathrm{CO})_{5}\right]^{+}$activated by collisions with a stainless steel surface. (Figure adapted from DeKrey et al. [12] with permission of John Wiley \& Sons Ltd.)

were ideally suited for this type of work because they exhibit consecutive fragmentation with minimal or no competitive reactions [10]. For a given fragment ion the ratio of the relative abundance of the fragment ion to the energy range over which it is formed is used to estimate the average internal energy that must have been deposited into the projectile ion [10, 11]. From a series of these single probability values a distribution can be estimated, allowing for a measure of the overall average internal energy of the projectile ions [10, 11]. This thermochemical method was used to compare single-collision CID to SID. As seen in Figure 3, SID provides variable controlled ion internal energy with increasing collision energy [12]. In addition it was also shown that the average internal energy deposited changes linearly over a broad range of collision energies [13].

Although the thermometer method is advantageous in the calculation of energy deposition, it is limited by the number of small molecules with simple consecutive fragmentation pathways for which it can be applied. To increase the potential molecular candidates for energy deposition calculations, an extended deconvolution method was implemented by Vekey et al. [14]. This method allowed the incorporation of competitive fragmentation pathways, thus enabling the calculation of energy deposition for a broader range of compounds with more complicated fragmentation schemes. Although analogous to the thermometer method, the deconvolution method relies on an experimentally determined breakdown curve of the ion rather than threshold appearance energies of fragment ions. The method is limited by the number of molecules with fully characterized breakdown curves [14].

After reports of SID fragmentation of well-characterized small molecules, larger simple cluster projectile ions were also characterized by SID. Whetten and colleagues probed the cleavage of sodium fluoride crystals by colliding mass selected clusters on surfaces. The ability to control the collision energies allowed for the determination of single-step low-energy cleavages. Magic numbers in the resulting fragments were observed that correlated to stable full crystal lattice structures [15]. The appearance of specific fragments at lower collision energies, as opposed to a distribution of products seen at higher energies, demonstrated the ability of SID to access a variety of fragmentation pathways that are dependent on the collision energy used [15].

With the applicability of SID to evaluate the fragmentation profiles of cluster ions, larger covalent molecules such as $\mathrm{C}_{60}$ became of interest. Whetten and colleagues found that unlike smaller ions and clusters, fullerenes did not exhibit fragmentation even at impact energies of $200 \mathrm{eV}$ [16]. These experimental results were bolstered by theoretical calculations. Mowery et al. [17] conducted molecular dynamics studies of $\mathrm{C}_{60}$ collisions on hydrogen-terminated diamond surfaces. It was shown that these large cluster molecules deformed upon collision with the surface but then exhibited resilience by regaining their cage-like structure upon recoil $[17,18]$. Figure 4 illustrates the structural changes of a $\mathrm{C}_{60}$ ion during the course of a $250-\mathrm{eV}$ collision with a hydrogen-terminated diamond surface [17].

Busmann and colleagues collided fullerene clusters at higher collision energies with a highly ordered pyrolytic graphite (HOPG) surface and found that unfrag- (a)

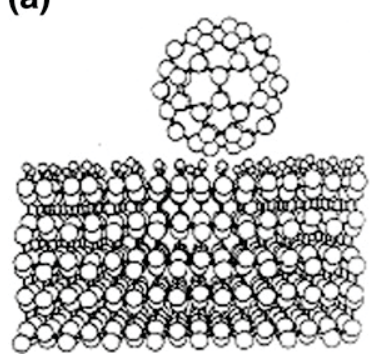

(b)

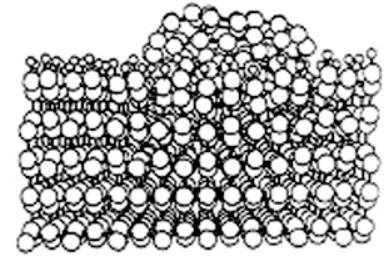

(c)
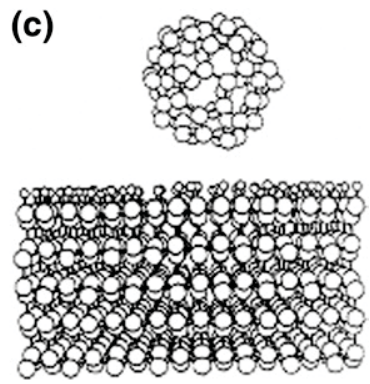

Figure 4. Atomic positions for a trajectory resulting in non-reactive scattering of $\mathrm{C}_{60}$ with a collision energy of $250 \mathrm{eV}$ (a) before ion-surface collision (14 fs), (b) during collision event (114 fs), and (c) after ion-surface collision (294 fs). (Figure adapted from Mowrey et al. [17] with permission of the American Chemical Society.) 
mented scattered ion intensity decreased with an increase of energy between 250 and $450 \mathrm{eV}$ [18]. These results also correlate with the molecular dynamics simulations of Mowery from which he suggests that above $250 \mathrm{eV}$ reactive collisions occur where the ions do not maintain enough center-of-mass translational energy to break bonds made with the surface, thus creating "chemisorbed" layers [17]. If there are molecules that gain enough internal energy for fragmentation, these bonds would break on the microsecond timescale, which is longer than the time frame of simulations and some of the experimental fragmentation studies undertaken of these fullerenes [17].

Fragmentation of large clusters was also found to be dependent on the surface chosen as the collision partner. Kappes et al. [19] found that graphite contaminated with hydrocarbon species gave low-mass sputter ions as well as influenced the overall fragmentation of the fullerene. Busmann [20] found a broader distribution of scattering angles for ions undergoing collisions with roughened diamond surfaces, whereas graphite surfaces gave a much more narrow angular distribution. Wysocki and colleagues [21] showed doubly charged $\mathrm{C}_{60}$ fragments at collision energies as low as $125 \mathrm{eV}$ on a fluorocarbon surface, illustrated in Figure 5a, noting that the ions were doubly charged and formed by thermal desorption/electron ionization, creating hotter ions, as opposed to the laser desorption used by Whetten [22]. When doubly charged fullerenes were collided on a hydrocarbon surface at the same collision energy, however, as shown in Figure 5b, a significant amount of one electron charge reduction of $\mathrm{C}_{60}{ }^{2+}$ was observed without the extensive fragmentation seen on the fluorocarbon surface [21]. Because $C_{60}$ is used as a projectile for secondary ion mass spectrometry (SIMS) there is continued interest in $\mathrm{C}_{60}$ collisions at a variety of surfaces and simulations of collisions at $\mathrm{keV}$ collision energies are still ongoing in the Garrison lab [23-26].

These experiments involving fullerene dissociation by SID highlighted the significance of surface selection. It may be advantageous to use a particularly "hard" surface that generates a large fraction of fragment ions or, conversely, a "softer" surface might be needed to retain precursor ion information. Several reports in the literature discuss "hard" versus "soft" surfaces that have been loosely defined by the amount of fragmentation and the resulting scattering angle of the fragments after colliding with the surface. Hard surfaces such as fluorinated self-assembled monolayers (SAMs) generate a population of SID fragments with a narrower angular scattering distribution, whereas softer surfaces such as hydrocarbon SAMs create broader distributions [27]. Fluorinated surfaces have been shown to exhibit unique characteristics when used as collision targets, which can be attributed to their terminal mass [27]. The larger terminal mass of a fluorocarbon SAM, compared to a hydrocarbon SAM, results in a larger amount of laboratory energy conversion into the vibrational en-
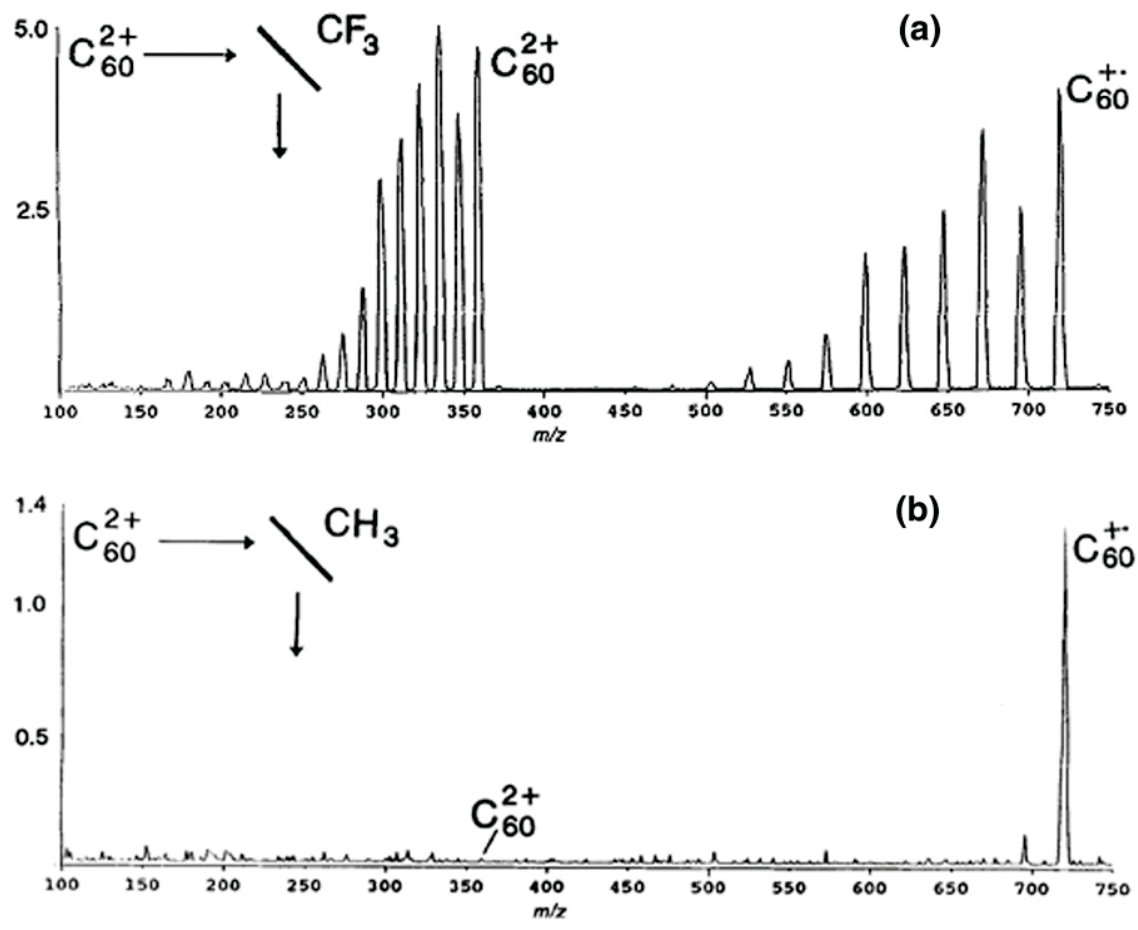

Figure 5. SID of $\mathrm{C}_{60}{ }^{2+}$ at $250 \mathrm{eV}$ collision energy on (a) fluorocarbon and (b) hydrocarbon self-assembled monolayers (SAMs). Collisions on the hydrocarbon surface show significant amounts of one electron charge reduction whereas collisions on the fluorinated surface show fragmentation of both the charge reduced ion and the doubly charged precursor. (Figure reprinted from Callahan et al. [21] with permission of John Wiley \& Sons Ltd.) 
ergy modes of a projectile ion when colliding on a fluorinated surface, about $20 \%$, as opposed to only $13 \%$ on a hydrocarbon surface [28]. The amount of energy imparted into projectile ions has also been studied using additional $\omega$-functionalized SAM surfaces to investigate the influences of film chain lengths, surface packing density on different substrates, and interfacial hydrogen bonding [29-35].

The neutralization efficiency of the surfaces is also an important determinant of a surface's utility in SID. Surfaces that exhibit a smaller amount of neutralization, such as fluorinated films, have a higher survival of resulting unfragmented projectile and fragment ions than those films that show a greater amount of electron transfer from the film to the projectile ions. The decrease in performance due to ion neutralization must therefore be taken into account along with the desired amount of fragmentation when selecting a surface partner for collisions.

CID has been used for the distinction of isomers. To more fully compare the utility of SID with CID it was important to show that ion activation by ion-surface collisions allowed comparable or better isomeric determinations. SID is attractive for the fragmentation of isomers because it requires only a single collision event that can minimize the effects of rearrangements. Cooks and colleagues demonstrated that isomer discrimination by SID was possible; they investigated a series of $\mathrm{C}_{2} \mathrm{H}_{4} \mathrm{O}$ molecules specifically by using the $\mathrm{MH}^{+}$precursor ion abundances relative to fragments [36]. This use of the ratio of the precursor ion abundances to fragment abundances as an additional tool for isomeric identification is possible for SID instruments that use an orthogonal configuration because every precursor ion must collide with the surface. The resulting percentages of fragments to precursor molecules represent a statistical distribution of fragmentation products to nondissociated precursor molecules in the absence of instrument discrimination effects. This is in contrast to CID, where the ambiguity in the number of collisions that each precursor ion undergoes does not allow for direct comparisons of ion abundances between the precursor ions and resulting fragment ions.

Another unique advantage of SID is that some peaks in the MS/MS spectra do not come from simple fragmentation of the precursor molecule. For odd-electron precursors, reactions may occur between the projectile ions and surface adsorbates. Although the resulting ions are typically discussed as a distinct process of ion-surface reactions, these products are inextricably convoluted into SID spectra and can be an additional asset in studying projectile fragmentation when ionsurface collisions are the ion activation method. Some ion-surface reactions such as radical $\mathrm{H}$ and $\mathrm{CH}_{3}$ abstractions from the surface can be used as diagnostic peaks for the distinction of isomers. For the spectra of $\mathrm{C}_{6} \mathrm{H}_{6}$ isomers shown in Figure 6, the peaks at $91 \mathrm{~m} / \mathrm{z}$ originate from an abstraction of $\mathrm{CH}_{3}$ followed by a subsequent loss of a neutral $\mathrm{H}_{2}$ molecule [37]. The abstraction product ion abundances relative to that of the remaining intact precursor ions are clearly different and their appearance in SID mass spectra can be an important tool for isomer distinction. Cooks and colleagues used the presence of these reaction products in SID spectra to characterize isomers of furanocoumarins (heterocyclic aromatics). They found that even though product ion spectra acquired by high-energy CID could differentiate between linear and cyclic precursors, additional isomers were indistinguishable. Isomers activated by SID, however, reacted differently and generated distinct product/precursor ratios. The use of these reaction peaks allowed the distinction of more isomeric compounds by SID than that by CID [38]. These reaction products are advantageous for projectile ion distinction and are dependent on the surface composition. For this reason it is important to characterize the surfaces used in ion-surface collisions to appropriately select surface collision partners used in SID experiments.

\section{Reactive Ion Scattering Spectrometry (RISS)}

Reactions can occur between terminal chemical moieties of organic thin film surfaces and the incoming projectile ions at hyperthermal energies (1-100 eV) at which bond cleavage and bond formation can occur. The RISS technique can characterize the surfaces used as collision partners by using well-characterized projectile ions. The information gained from these experiments is essential to maximizing the potential control of SID where reaction peaks can be enhanced or diminished depending on the goals of the experiment. Types of reactive projectile ions vary from atomic species such as $\mathrm{Cs}^{+}$used extensively by Kang and colleagues in an ultrahigh vacuum (UHV) chamber [39-42] to polyatomic ions. Abstractions of $\mathrm{CH}_{3}$ and $\mathrm{H}$. from the surface are particularly useful reactions seen with oddelectron polyatomic projectile ions because not only can they be used to characterize hydrocarbon films but they can also be used to indicate the cleanliness of thin films containing hydrocarbon as a contaminant. Surfaces used as collision targets for MS experiments within the pressure range of $10^{-6}$ to $10^{-7}$ Torr can become contaminated with adventitious hydrocarbons from pump oil [43] or from organics used in experiments [44-46]. Ion-surface collisions of fullerenes on contaminated highly ordered pyrolytic graphite (HOPG) showed this technique to be a more sensitive means of detection of sputtered hydrocarbons than low-energy electron scattering; moreover, the cleanliness of the surface had a direct impact on the scattering of $\mathrm{C}_{60}$ clusters, as mentioned previously [20].

Reaction products containing surface components such as methyl and hydrogen atoms can also be used to monitor orientation of groups at the surface, as shown by reactivity results obtained for odd and even chain length films [47]. SAM films of hydrocarbon adsorbates on gold have well-defined terminal orientations based on their intrinsic tilt angles upon adsorption, as de- 

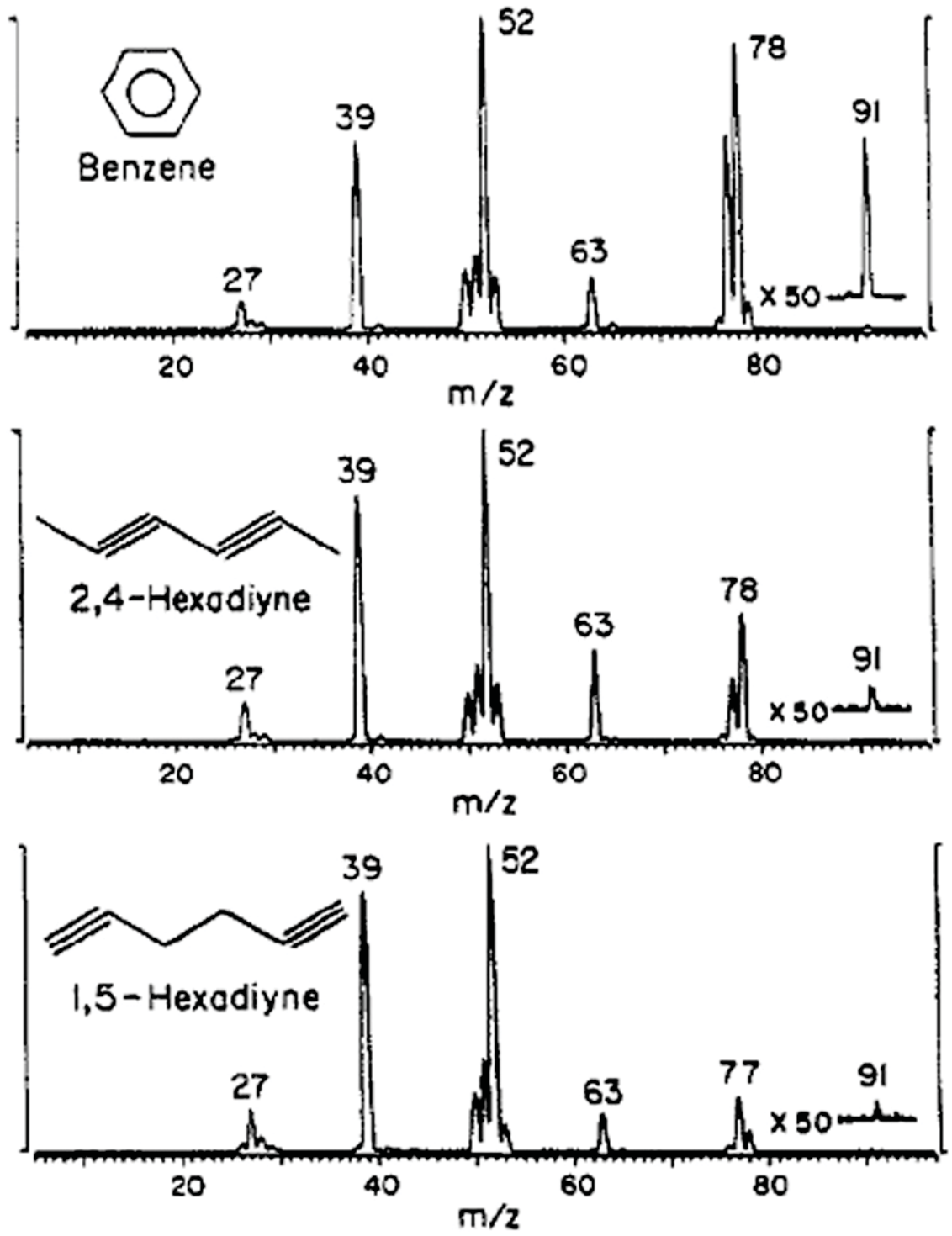

Figure 6. Isomers of $\left[\mathrm{C}_{6} \mathrm{H}_{6}\right]^{+}$collided at $35 \mathrm{eV}$ on stainless steel surfaces. The $91 \mathrm{~m} / \mathrm{z}$ inset shows reaction peaks used for further differentiating isomers beyond visual fragmentation profiles. (Figure reproduced from Hayward et al. [37] with permission from the American Chemical Society.)

picted in Figure 7a [47]. For odd chain length SAMs, the terminal carbon-carbon bond is approximately parallel to the surface. This exposes a more perpendicular $\mathrm{H}-\mathrm{C}$ bond to the projectile ions and results in an increased observance of $\mathrm{H}$ abstraction reaction product ions. An even chain length hydrocarbon SAM has terminal C - C bonds approximately perpendicular to the surface. This creates a more probable reaction between incoming projectile ions and exposed surface carbon atoms leading to increased methyl abstractions, as shown in Figure $7 \mathrm{~b}$ [47].

In addition to odd/even reactivity differences, it has been shown by Wysocki and colleagues [43] that the interaction of the projectile ion is predominantly isolated to the terminal carbon atoms. Terminally labeled Langmuir-Blodgett (LB) film methyl groups $\left({ }^{13} \mathrm{CH}_{3}\right.$ and $\mathrm{CD}_{3}$ ) were interrogated by reactive ion collisions by a variety of both deuterated and non-deuterated projectile ions [43]. Abstraction products showed clear mass shifts for the incorporation of the labeled methyl groups. Additionally, LB films of $\mathrm{CD}_{3}\left(\mathrm{CH}_{2}\right)_{16^{-}}$and $\mathrm{CD}_{3}\left(\mathrm{CD}_{2}\right)_{16}$ - gave remarkably similar abstraction products, showing that the ion beam probes predominantly the uppermost surface at low collision energies.

\section{Peptides and Proteins}

Mass spectrometry emerged as a tool to study peptide structure in the early to mid-1980s with the development of "soft" ionization techniques such as fast atom bombardment (FAB) [48, 49], electrospray ionization (ESI) [50], and matrix-assisted laser desorption ionization (MALDI) [51]. Because these methods predominantly produced molecular ions with little fragmenta- 
(a) even odd

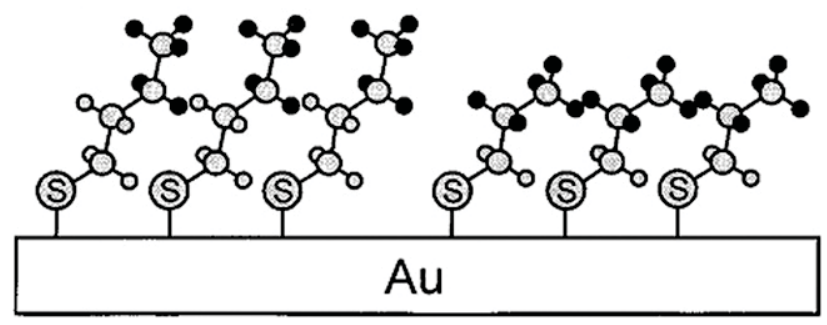

(b)

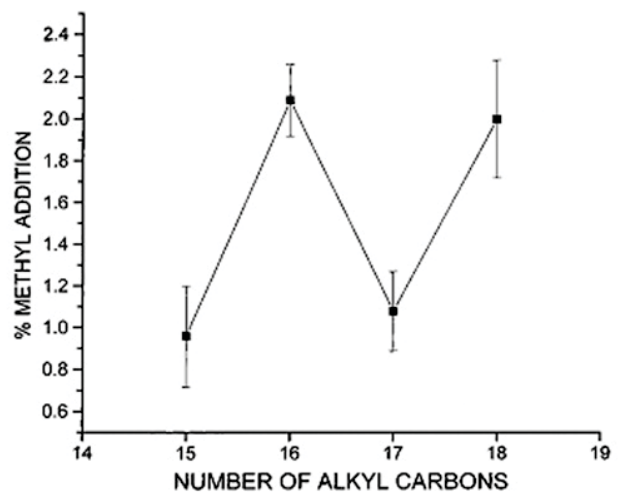

Figure 7. (a) Pictorial representation of alkyl SAMs on gold showing terminal carbon-carbon bond orientation with respect to incoming projectile ions and (b) percentage methyl addition observed on odd and even chain biphenyl alkyl SAMs with 20-eV collisions of pyrazine. (Figure adapted from Angelico et al. [47] with permission of the American Chemical Society.)

tion, few structural details were available from a single stage of mass spectrometry. Consequently, tandem mass spectrometry became essential for the structural characterization of biological molecules. The ability to ionize peptides and proteins was met with the realization that traditional methods of activation, such as collision-induced dissociation (CID), did not always provide extensive fragmentation for large biological ions, especially singly charged ions above approximately 3000 Da [52-54]. Although the upper mass limit of CID has since been overcome through the increased use of multiple collisions in CID and the ease of fragmenting multiply charged ESI-generated proteins [55], these difficulties in the early days of biological mass spectrometry opened the door for alternative fragmentation methods to be explored.

Advances in sample ionization coincided chronologically with the first routine application of SID in a tandem mass spectrometer by Cooks and colleagues [3]. Early SID studies conducted with small molecules demonstrated efficient conversion of the ion's translational energy into its internal degrees of freedom (e.g., kinetic to internal energy), suggesting SID could be a promising method for fragmenting larger, biological species. This led several research groups to investigate the potential of SID for use in peptide and protein activation. Indeed, collaborative work between the McLafferty and Hunt groups and studies from our own laboratory verified that extensive sequence coverage could be achieved for large peptides such as RSBP (MW 3054) and Porcine ATCH (MW 4568) upon surface collision [56, 57]. McLafferty and colleagues [58] also demonstrated the effectiveness of SID as an activation method for multiply protonated proteins, fragmenting 29-kDa carbonic anhydrase.

Despite this success, SID has not been incorporated into commercial mass spectrometers, preventing widespread application outside of labs willing to build and develop their own instrumentation. SID has nevertheless proven its worth in fundamental studies of fragmentation mechanisms and energetics, especially in the case of peptides for which accurate activation energies are difficult to estimate. An important feature of SID is the deposition of a well-defined internal energy distribution that can be finely varied by changing the laboratory collision energy. This tunability reduces the uncertainty in the amount of internal energy deposited upon activation, providing a method to reliably measure relative energies for fragmentation processes.

\section{The Role of SID in Developing the Mobile Proton Model and Elucidating Peptide Fragmentation Mechanisms}

Protein sequencing by mass spectrometry was realized over 25 years ago [59-61]. Since that time, improvements in sequencing have been spurred by the development of protein-identification algorithms as well as a better understanding of peptide dissociation in the gas phase. The latter advancement has been achieved by exploring the effects of peptide size, sequence, gasphase basicity, charge state, and secondary structure on fragmentation [62-70]. Surface-induced dissociation was influential in helping to develop a general framework for peptide fragmentation through the energyresolved study of systematically varied model peptides. SID results from the Wysocki group contributed to the mobile proton model, a description of peptide dissociation in which fragmentation is initiated by rapid intra-molecular proton transfer among backbone protonation sites.

Evidence for the mobile proton model is illustrated by the relative fragmentation energetics of four pentapeptides (sequence XAAAA, where $\mathrm{X}=\mathrm{A}, \mathrm{P}, \mathrm{K}$, or $\mathrm{R}$ ) shown in Figure 8a [65]. Each peptide was fragmented by SID on a gold surface coated with a fluorinated SAM film. Their relative fragmentation was compared by plotting the fragmentation efficiency curves (FECs, plots of percentage fragmentation versus laboratory collision energy) for each peptide. The inflection point energy, defined as the laboratory collision energy corresponding to $50 \%$ fragmentation of the precursor ion, can be used to provide a single point comparison for relative fragmentation. In this case, clearly the inflection point energies of these four peptides are shifted in accordance with the gas-phase basicity of the $\mathrm{N}$-terminal amino 

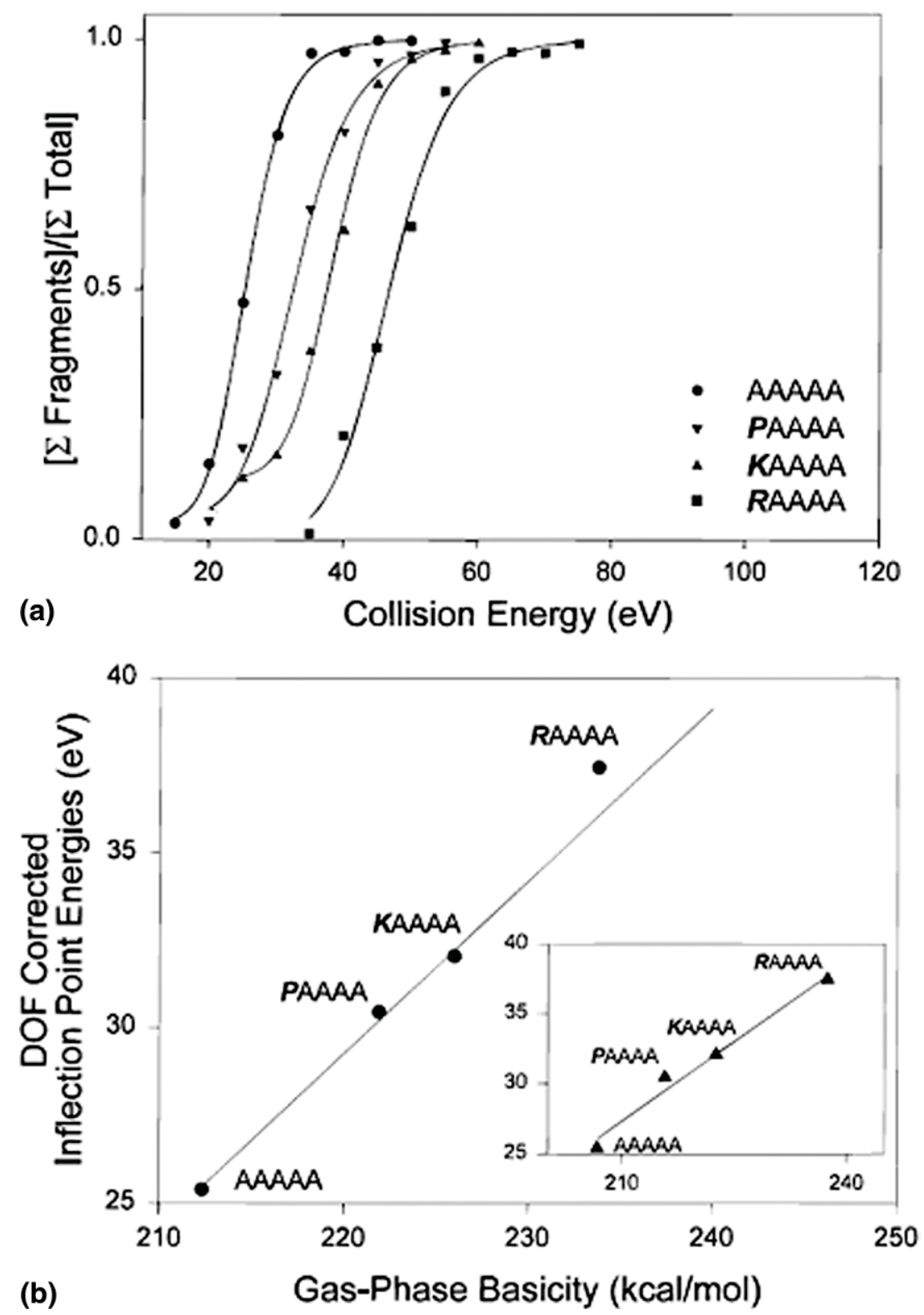

\begin{abstract}
Figure 8. (a) Fragmentation efficiency curves of the $[\mathrm{M}+\mathrm{H}]^{+}$ion for four alanine containing

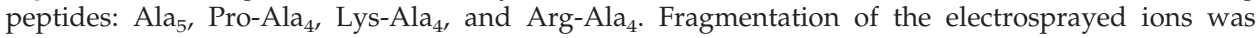
performed in a tandem quadrupole instrument via SID. (b) The DOF-corrected inflection point energies from (a) plotted against the gas-phase basicity of each peptide. (Figure reproduced from Dongre et al. [57] with permission from the American Chemical Society.)
\end{abstract}

acid residue. This is consistent with the idea that when a proton is more tightly sequestered at the site of greatest basicity, more energy is necessary to mobilize the proton and induce fragmentation. Consequently, the energy required to fragment a peptide increases along with the gas-phase basicity of the ion (non-basic peptides $<$ Pro at the $\mathrm{N}$-terminus $<$ Lys-containing $<$ Arg-containing). If this inflection point energy is corrected for the number of degrees of freedom (DOF) in each peptide, fragmentation energetics can be compared between peptides of various sizes, revealing differences due solely to chemical properties such as gas-phase basicity. It then becomes clear that there is a linear correlation between the DOF-corrected energies and the gas-phase basicity of the peptides (Figure $8 b$ ) $[65,71-74]$.

SID experiments have also played an essential role in characterizing residue-specific peptide cleavages. As the number of tandem MS peptide studies increased, several researchers began to notice enhanced fragmentation at particular amino acid residues that prevented complete backbone cleavage, and resulted in incomplete sequencing information [59, 62, 64, 68, 70, 75-78]. Protein-identification algorithms may benefit from the incorporation of selective cleavage rules if residuespecific influences are more completely understood. 
Studies in our research group focused on characterizing why certain residues cause enhanced cleavages and examined the prevalence of those cleavages over a variety of instrument time frames and activation methods, including SID. For example, the presence of aspartic or glutamic acid in a peptide commonly causes cleavage on the C-terminal side of the acidic residue, particularly when arginine is also present within the peptide and the number of added protons is less than or equal to the number of arginine residues. SID studies of peptides containing acidic residues illustrated that if the number of ionizing protons were equal to the number of Arg residues, then the arginine(s) could sequester the proton(s), thus allowing the acidic hydrogen on the aspartic or glutamic acid side chain to initiate backbone cleavage $[79,80]$. Figure 9a shows SID spectra of singly protonated LDIFSDFR (Figure 9a) and LDIFSDF (Figure 9b). The former contains one Arg and two Asp residues, and shows selective cleavage at the $\mathrm{C}$-terminus of each aspartic acid to preferentially yield $\mathrm{y}_{2}$ and $\mathrm{y}_{6}$ ions. The
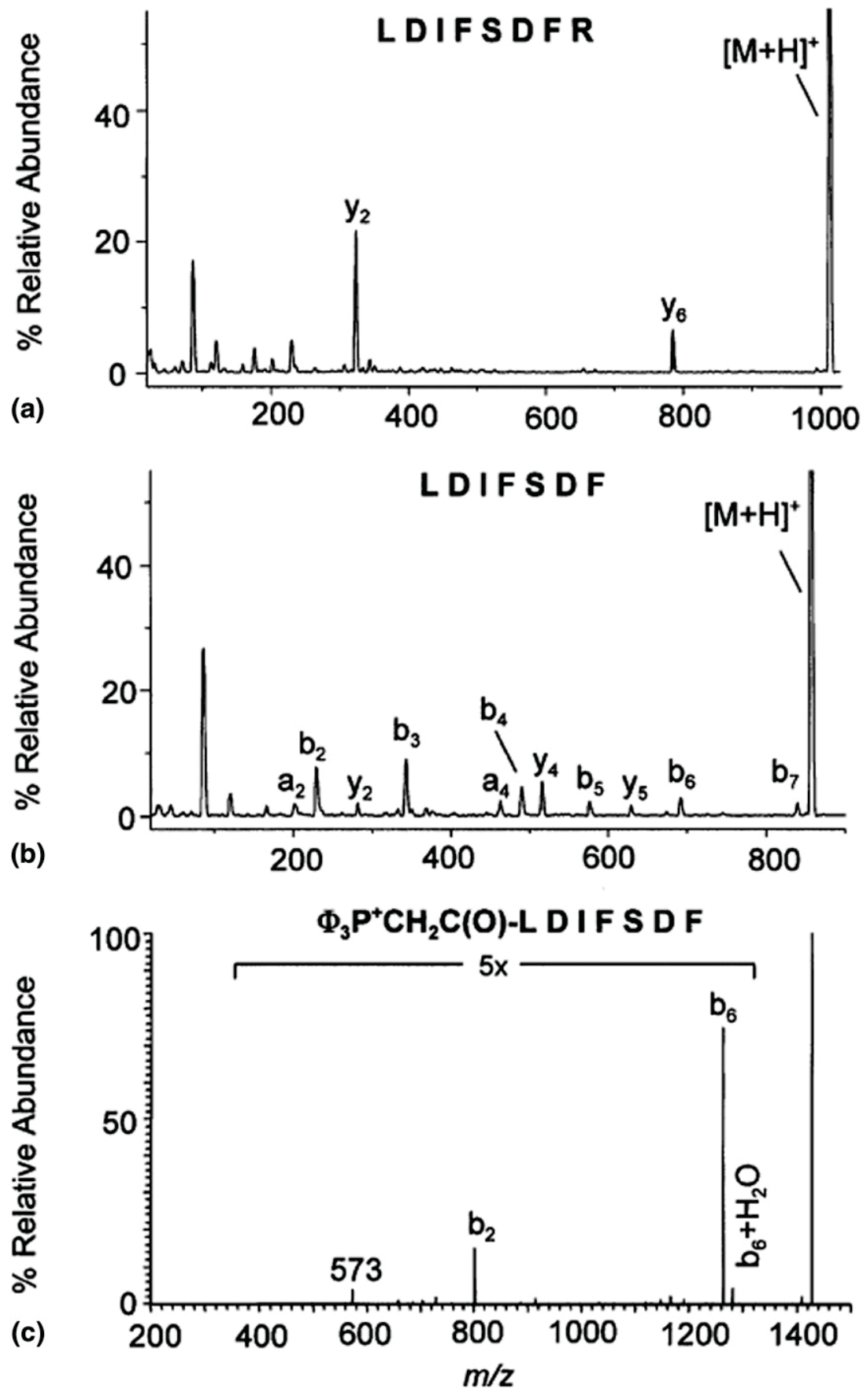

Figure 9. SID spectra of singly protonated LIDFSDFR (a), LDIFSDF (b), and the fixed charge derivative $\Phi_{3} \mathrm{P}^{+} \mathrm{CH}_{2} \mathrm{C}(\mathrm{O})$-LDIFSDF acquired on a quadrupole ion trap (Thermo LCQ). (Figure adapted from $\mathrm{Gu}$ et al. [79] with permission of the American Chemical Society.) 
latter peptide has the same sequence at residues $1-6$ but contains no arginine, and non-selective cleavage occurs along the peptide backbone. When the peptide analyzed in Figure $9 \mathrm{~b}$ is derivatized to add a fixed charge at the N-terminus, selective cleavage is once again observed at each Asp because the charge can no longer be mobilized (Figure 9c).

A statistical analysis of over 28,000 tryptic peptide ion trap tandem mass spectra of singly, doubly, and triply charged peptides confirmed the common trends observed in model peptide studies [70], and agrees with a related study of doubly charged peptides [81]. The factors with the greatest influence on peptide dissociation are the mobility of the proton, the position and basicity of the most basic residue, and the presence or absence of proline. Doubly charged peptides are far more likely to contain a mobile proton and follow the random cleavage model upon which sequencing algorithms are based, whereas singly charged peptides demonstrate a greater dependence on the basicity of the C-terminal arginine or lysine. In the case of singly charged tryptic peptides, Lys-ending peptides are far more likely to have a heterogeneous population of protonated forms, or a "partially mobile proton," whereas Arg-ending peptides can more completely sequester the proton at the guanidinium group [81]. When the proton is mobile or partially mobile, cleavage $\mathrm{N}$-terminal to proline, if present, dominates the product ion spectra. When proline is not present, enhanced cleavage is observed at other residues that have atypical Ramachandran $\Phi, \Psi$ plots, indicating a steric influence on fragmentation [68]. If the proton is sequestered at a basic residue, the trend of enhanced cleavage $C$-terminal to acidic residue dominates, as observed for the model peptide in Figure 9a. In this case, enhanced cleavage at Asp, Glu was found to be more dominant in Arg-ending tryptic peptides than in Lys-ending tryptic peptides, a statistical correlation consistent with the notion that protons are more tightly sequestered by the more basic side chain of arginine. Although current computer algorithms ignore much of the chemically meaningful relative intensity information available in a tandem mass spectrum, the success rate of protein identification might be improved by taking into account the chemical properties of individual amino acid residues.

Additional efforts to improve protein identification and characterization have promoted novel developments in SID instrumentation. Russell's group has shown SID to be a simple, yet effective method of activating ions in ion mobility-orthogonal time-of-flight instruments [82-84]. The advantage of these instruments is that complex proteomic samples can be separated in the gas phase by ion mobility followed by comparatively faster MS and tandem MS analyses as species exit the mobility drift cell. This allows simultaneous acquisition of peptide molecular masses and sequence information in a single experiment. The incorporation of SID as the activation method is cost-effective and relieves the need for bath gas, simplifying experiments conducted with high- resolution TOF mass analyzers. It also provides finer, more reproducible control over the fragmentation chemistry of peptide samples than does CID.

Implementation of SID in an FT-ICR instrument has been shown to improve high throughput peptide dissociation [85]. Unlike sustained off-resonance irradiation (SORI)-CID, the gas-free nature of SID allows LC/MS/MS studies to be conducted without the need to pump down the ICR cell, thus increasing the rate of spectral acquisition. This allows a greater number of precursor ions to be selected for MS/MS within a single chromatographic peak. High-resolution SID is particularly amenable to patchwork efforts that have been used to improve protein identification. The concept of the patchwork approach is to use accurately identified fragment ions in the low $\mathrm{m} / \mathrm{z}$ region of tandem mass spectra as compositional qualifiers in peptide sequencing [86]. These qualifiers, consisting mainly of $\mathrm{a}_{2}, \mathrm{~b}_{2}, \mathrm{y}_{1}$, $\mathrm{y}_{2}$, and internal and immonium type ions, provide additional restraints during database searching that help ensure the correct peptide is identified. Fernandez et al. [87] demonstrated that SID in an FT-ICR yielded a large number of these qualifier ions, improving the statistical significance of database searches. In addition, SID conducted on a diamond surface provided improved sequence coverage over SORI-CID resulting from the accessibility of both fast and slow dissociation pathways not readily accessible by CID. The wide energy distribution reported was attributed to the energy deposition properties of the diamond collision target itself. This highlights the importance of understanding the role that the surface plays in the study of peptide dissociation. Although fundamental aspects of ion-surface collisions involving small molecules were discussed earlier, a number of studies have focused on the effects of extending SID to ions of increasing mass and the influence of surface composition on the dissociation of biological molecules.

\section{Characterization of Energy Deposition in Peptide Ion-Surface Collisions}

The view of the surface as a nearly infinite collision partner implies that ion activation should essentially be independent of mass, making SID potentially even more attractive for the study of large projectile ions such as peptides and proteins [88, 89]. As mentioned earlier, however, this assumption is not always valid and several attempts have been made to understand energy conversion in SID as it pertains to biological molecules. Energy transfer in SID has also been addressed in terms of the distribution of internal energy deposited into the ion population. An understanding of these characteristics and how they are affected by ion mass is essential for comparing SID with other activation methods or evaluating different types of surfaces.

Although thermometer ions were used to characterize energy deposition in SID of small molecules, the 
dissociation pathways of peptides are far more complicated. The deconvolution method of Vekey et al. [90], mentioned in the small molecule section, has also been used to estimate activation energies for the dominant fragmentation channels of several peptides. By estimating the internal energy of a peptide ion based on the extent of fragmentation, the kinetic to internal energy conversion upon collision with a given surface can be estimated. Laskin, Denisov, and Futrell $[7,91]$ have shown that SID collision energy can be converted to an "effective" center-of-mass energy scale by superimposing the SID and multiple-collision CID fragmentation efficiency curves and using an arbitrary value of $\mathrm{M}_{\mathrm{N}}$ to represent the surface collision partner. When comparisons between the SID and CID fragmentation efficiency curves for a series of small alanine-containing peptide ions were made in the center-of-mass reference frame, the best overlap was observed using an effective surface mass between 39 and 46 for all peptides colliding with a fluorinated SAM [7]. This implied that the energy transfer in SID is not independent of projectile ion mass, but that kinetic to internal energy conversion decreases with increasing molecular size. Although the arbitrary value of $\mathrm{M}_{\mathrm{N}}$ given to the surface in these experiments has no physical significance, it indicates that perhaps the surface is more appropriately defined in terms of an "effective" mass than as a bulk collision partner of essentially infinite mass, and that the mass of the terminal chemical moieties on the surface (i.e., the $\mathrm{CF}_{3}$ group of a fluorinated SAM) dictate how much internal energy is deposited [4]. As mentioned earlier, the Wysocki group [5] has also found the terminal groups of SAM films to have the most effect on the extent of kinetic to internal energy conversion, although the underlying chemical groups also appear to play a secondary role.

Laskin, Futrell, and colleagues [91-94] have developed a method for defining the energy deposition function of an activation process that combines RRKM modeling with experimental MS/MS data to define the distribution of internal energy deposited into a peptide ion population. In this approach, the energy deposition function is determined by simulating a breakdown curve based on the microcanonical rate constants for each dissociation channel. The simulated curves are compared to experimentally obtained fragmentation efficiency curves until the best fit is achieved. The energy deposition function has been used to compare SID with multiple-collision CID and to explore the utility of different surfaces in peptide SID. Although SID has been shown to offer a narrow internal energy distribution relative to single-collision CID [95, 96], Laskin, Futrell, and colleagues have found that internal energy distributions for SID and multiple-collision SORI-CID in an FT-ICR are similar [91, 97]. They have also demonstrated that the width of the energy deposition function in SID is dramatically affected by the stiffness of the surface. The modeled energy deposition function of a hydrocarbon SAM film, which is approx- imately equivalent to a thermal distribution of energies, was found to be 1.6- and 2.3-fold narrower than the energy deposition functions of stiffer $\mathrm{LiF}$ and diamond surfaces, respectively [4].

Experimental studies of peptide SID have been supported by increasing efforts to characterize energy transfer through simulations of peptide ion-surface collisions [98-102]. Hase and colleagues have shown that several factors affect kinetic to internal energy conversion in the SID process, including collision energy, peptide size and conformation, incident collision angle, and surface target. Classical trajectory simulations of protonated diglycine and dialanine demonstrated that internal energy transfer in normal-incidence SID (collision perpendicular to the surface) decreases slightly with increasing collision energy [101, 102]. The influence of peptide size has been explored by examining collisions of polyglycine $\left(\mathrm{gly}_{n}-\mathrm{H}^{+}, n=1-5\right)$ with a diamond surface. The percentage of energy transfer into the peptide's internal modes was found to be slightly greater for larger peptides due to the greater number of vibrational modes $[98,102]$. The angular dependence of SID has been explored by varying the incident angle from 0 to 45 degrees (with zero representing a collision perpendicular to the surface), which resulted in a decrease in energy transfer to internal modes of diglycine. Simulations from the Hase group have also helped to define the role of the surface in SID by studying not only internal energy deposited into the projectile ion, but also transfer into vibrational modes of the surface. In a comparison of diamond and $n$-hexyl thiolate SAM surfaces, the SAM film was found to absorb a far greater percentage of the projectile ion's initial kinetic energy [98]. SID of folded $(\mathrm{Gly})_{3}$ resulted in transfer of $63 \%$ of the kinetic energy into the SAM film as opposed to only $9 \%$ into the stiffer diamond surface. The majority of the energy in the collision with diamond remained as translational energy of the fragment ions. The diamond surface was found to be more efficient for activation, transferring approximately twice the amount of internal energy into the projectile ion as the $n$-hexyl thiolate SAM film. What becomes clear from these theoretical studies is that experimental work over a wide range of surface compositions, collision angles, and ion types is necessary to characterize energy deposition in SID.

\section{Kinetics of Peptide Fragmentation}

Collisional activation, whether by gas or surface, is generally considered to occur via two steps: (1) activation via collision with the target and (2) unimolecular dissociation some time after the activation step, once the ion has traveled away from the collision target. The observation of fragment ions in an MS/MS experiment is dependent on the rate of the dissociation of the precursor ion and the timescale of the mass spectrometer. Typically, excess energy above the activation barrier must be added for fragmentation to be observed on the timescale of the mass spectrometer, a phenomenon 
known as the kinetic shift. Because the observation time frame in a mass spectrometer can range from nanoseconds to several seconds or longer, the amount of internal energy that must be added to overcome the kinetic shift varies from instrument to instrument. Consequently, dissociation products can differ substantially when produced on the microsecond timescale of tandem quadrupole SID instruments versus those generated in trapping mass spectrometers. Recently, there has been evidence to suggest that some peptides may fragment by an alternative dissociation process known as shattering, in which fragmentation occurs nearly instantaneously while ions are still in direct contact with the surface. Full understanding of the SID process requires knowledge of the timescale on which dissociation occurs and must be studied using instruments with different observation time windows.

Time-resolved SID studies have been conducted in an FT-ICR by varying the trapping time following peptide ion-surface collision [103-106]. These studies revealed the time dependence of peptide fragmentation when the observation time frame ranged from $1 \mathrm{~ms}$ to several seconds. The fragmentation efficiency curves for some fragment ions, however, proved to be independent of the timescale. The time-dependent fragments were formed through statistical RRKM-type unimolecular decay at low collision energy, whereas the formation of time-independent fragments was attributed to an instantaneous shattering of peptides at the surface under high-energy conditions. It should be noted, however, that in this case "time-independent" means only that the protonated peptides had fragmented faster than the millisecond minimum detection time in the FTMS instrument.

Simulations performed by Hase and colleagues have supported evidence of a shattering fragmentation mechanism given the appropriate laboratory energies, collision angles, and surfaces [99-101, 107]. Simulations of glycine colliding with a diamond surface revealed that as much as $55 \%$ of the total fragmentation observed could be attributed to shattering at the surface [99]. For simulations on diglycine, the shattering mechanism resulted in an increase in the number of fragmentation channels available from 6 at $30 \mathrm{eV}$ to 59 at $100 \mathrm{eV}$ and was strongly influenced by the orientation of the diglycine molecule as it collided with the surface [101].

Typically, unimolecular dissociation alone has been reported to dictate the SID product ion spectrum with no evidence of shattering. Hanley and colleagues [108], who used an axial energy analyzer to measure the kinetic energy distributions of fragment ions, determined that peptide dissociation occurs away from the surface rather than during direct surface contact. In contrast to small-ion SID, in which evidence of shattering was provided by the scattering of products with different velocities but similar energies [109], peptide fragments were shown to possess a common velocity. This indicates, according to the conservation of momen- tum, that larger peptide ions must decompose only after leaving the surface.

Gamage et al. [110] investigated peptide fragmentation kinetics by performing SID in a MALDI-TOF specifically designed for observing sub-microsecond fragmentation products. SIMION trajectory simulations of precursor and product ions were used to estimate fragmentation time based on the experimentally observed surface-to-detector flight times of peptide fragments. Gamage et al. proposed that these fast fragmentation processes occur on the nanosecond timescale, corresponding to a fragmentation distance of 1-3 $\mathrm{mm}$ away from the surface and a $\log k$ of 7 based on peak shape analysis. No experimental evidence of instantaneous dissociation was observed.

\section{Protein Complexes}

In recent years the mass spectrometric analysis of non-covalent macromolecular complexes has rapidly grown into an exciting area of research. Through the contributions of a number of different research groups, numerous non-covalent assemblies have now been investigated in the gas phase [111-117]. The wide array of non-covalent systems that have been studied include complexes as simple as small protein-protein dimers and assemblies as daunting as the intact 705 ribosome, a heterogeneous 2 MDa complex composed of several RNA and over 50 different proteins $[113,116]$. Regardless of the complex, analysis by mass spectrometry has typically required nanospray ionization of the analyte from "near-physiological" (i.e., neutral pH) conditions. Furthermore, the efficient transmission of these large ions hinges on the use of elevated source pressures to provide collisional focusing in the source region [118]. In many of these studies the mass-selected complexes have been fragmented using collision-induced dissociation (CID), typically with argon as the target gas. It has been shown in numerous studies with a variety of protein-protein complexes that CID causes highly asymmetric dissociation with respect to both mass and charge [112, 114, 119]. Typically, the predominant dissociation products observed are a monomer and $(n-$ 1)mer (where $n=$ the oligomeric state of the precursor ion) with each ion retaining a nearly equal number of charges despite the large difference between their molecular weights. From a practical standpoint, this dissociation pathway limits the amount of structural information that can be derived from MS/MS spectra. Furthermore, this unusual phenomenon has sparked a flurry of research seeking to better understand how large non-covalent assemblies dissociate in the gas phase. Through the work of a number of groups the general hypothesis that has emerged explains asymmetric dissociation by a pathway that must involve gasphase proton transfers and significant unfolding of the ejected monomer [112, 114, 120]. Although the precise details of what drives this process are still a matter of debate, it is generally agreed upon that protein unfold- 
ing must occur to increase surface area and relieve the Coulomb repulsion induced by the disproportionate number of charges (protons) that are typically carried away by the ejected subunit [112, 114, 120].

In light of the recent interest in the activation and dissociation of gas-phase complexes, our group has begun probing these phenomena via surface collisions. Unlike the common ion activation methods that have been used previously, by which internal energy is deposited gradually in multiple steps [121], SID takes place following a short time-frame collision event with a surface as depicted in Figure 2. If a protein subunit unfolds during the multiple gas-phase collisions provided by CID then it is expected that the transition-state structure of this dissociation reaction would be quite different from that of a folded monomer being ejected. Furthermore, an unfolded monomer is likely to be bound less tightly due to the disruption of its native binding interfaces. Therefore, once unfolded, likely expulsion of this subunit would have a lower activation barrier than expulsion of a folded protein subunit where the integrity of its binding interfaces remains relatively intact. This is not to say that the entire pathway involving monomer unfolding is energetically less demanding than a direct dissociation pathway that does not require disruption of tertiary structure. In fact, monomer unfolding is likely to be energetically demanding. The reason that this pathway may be favored in CID is due to the small steps in which the ion is activated, each of which is not sufficient to cause dissociation, but may affect the structures before dissociation. We have hypothesized that if stepwise unfolding occurs through a series of incremental increases in energy then it should be possible to access the direct dissociation pathway (i.e., without significant unfolding) by SID. In the latter case, sufficient internal energy can be deposited in a single collision event such that dissociation occurs before significant unfolding. Both the unfolding and direct (no unfolding) pathways could contribute to the overall spectrum, because the internal energy accessed may be higher than either of the barriers to dissociation.

This hypothesis was initially explored using noncovalent dimers of cytochrome c. The dimer of cytochrome c was chosen for its relative simplicity and because it was previously studied [114, 122]. In previous research, Williams and colleagues used a combination of SORI-CID and chemical cross-linking to demonstrate that upon activation and dissociation of the dimer only one of the subunits was likely unfolding [114]. For our investigation a quadrupole time-of-flight mass spectrometer (QTOF II, Waters) was modified to include an electrostatic device for SID [123]. This device was installed between the mass selection quadrupole and hexapole collision cell of the instrument. Ions can be either deflected toward the surface ("SID mode") or transmitted without a surface collision ("CID mode"). Therefore, the instrument is capable of both CID and SID experiments. In our initial experiments with this protein-protein dimer, the $11+$ precursor ion was mass selected and fragmented by CID, as can be seen in Figure 10a [124]. It is evident from this spectrum that the dimer favors dissociation into monomers possessing unequal charge states, with the formation of $8+$ and $3+$ fragment ions being the predominant pathway. This pathway was favored over a wide range of collision energies, spanning from 550 to $990 \mathrm{eV}$ in the laboratory reference frame. These results are quite similar to those of the published SORI-CID experiments [114], and also suggest that one of the subunits is unfolding (i.e., the $8+$ ion). It is not clear whether the unfolding is driven by Coulomb repulsion, or whether proton transfers are enhanced due to the increased surface area of the monomer. In contrast to CID, a surface collision produces a different spectrum. The SID spectrum in Figure $10 \mathrm{~b}$ demonstrates this effect, given that the predominant pathway is now the formation of the $6+$ and $5+$ fragment ions, the most symmetric pathway possible from an $11+$ ion. This symmetric dissociation pathway was observed from 330 to $990 \mathrm{eV}$ laboratory collision energies. If the highly asymmetric behavior induced by CID is indicative of extensive subunit unfolding, then the symmetrical dissociation observed by SID may suggest a more compact protein dimer structure in the dissociative transition state.

The dramatic differences observed between CID and SID of cytochrome c dimers led to the comparison of the dissociation behaviors of larger complexes. As described earlier, it is believed that SID of the dimer occurs with minimal subunit unfolding, as evidenced by the even distribution of charges. To study the partitioning of both mass and charge, we have compared the CID and SID of various tetramers, a pentamer, and several dodecameric small heat shock proteins. The dissociation of one of the tetramers, concanavalin A from jack bean, is shown in Figure 11. In solution, concanavalin A exists primarily as a dimer below $\mathrm{pH} 5.8$ and as a tetramer between $\mathrm{pH} 5.8$ and 7.0. Both the dimeric and tetrameric forms of the complex have been studied previously by Light-Wahl et al. [125], including dissociation of both gas-phase species in the capillary-skimmer region. Figure 11a shows the CID MS/MS spectrum of the 22+ tetramer ion $\left(\mathrm{Q}^{22+}\right)$. In general, $\mathrm{CID}$ has been shown to induce highly asymmetric mass and charge partitioning upon dissociation of nearly all protein complexes studied thus far. This is indeed the case here because the $22+$ tetramer yields primarily monomer $(\mathrm{M})$ and trimer (T) product ions with the monomer retaining approximately half the charge. The SID spectrum of this complex is shown in Figure $11 \mathrm{~b}$ and is strikingly different from the CID spectrum. Collision of the $22+$ tetramer with a surface produces solely monomeric product ions at a collision energy of $2310 \mathrm{eV}$. Whereas the monomers ejected by CID retain approximately half of the overall charge of the precursor ion, the monomers produced via SID have an average charge state of 5.8. This corresponds to about $26 \%$ of the overall charge of the initial precursor, indicating the charge is nearly evenly 


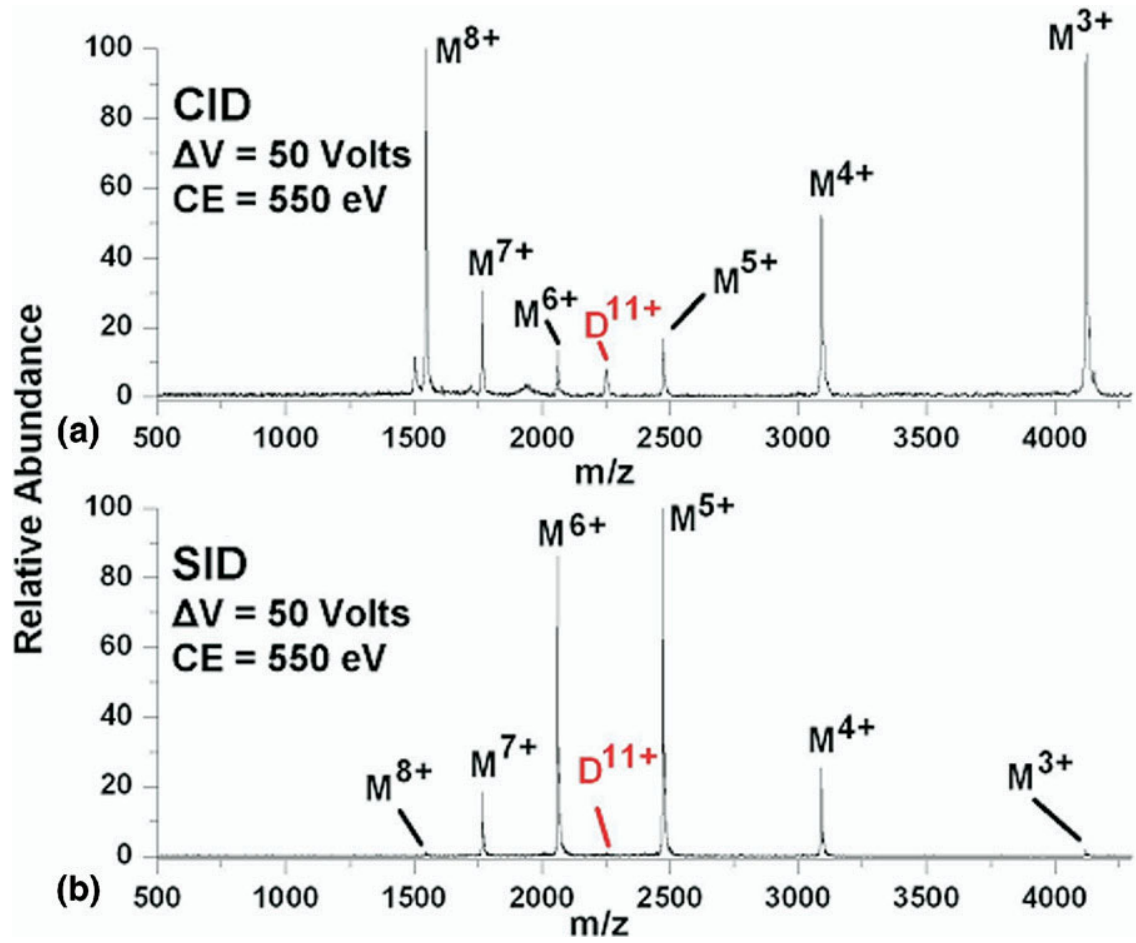

Figure 10. Comparison of CID (a) and SID (b) tandem mass spectra of the 11+ dimer of cytochrome $\mathrm{C}$. The voltage difference between the source hexapole and collision cell or surface is shown as $\Delta \mathrm{V}$. The laboratory collision energy (CE), calculated as the product of the collision voltage and precursor ion charge state, is also provided with each spectrum. (Spectrum adapted from Jones et al. [124] with permission from the American Chemical Society.)

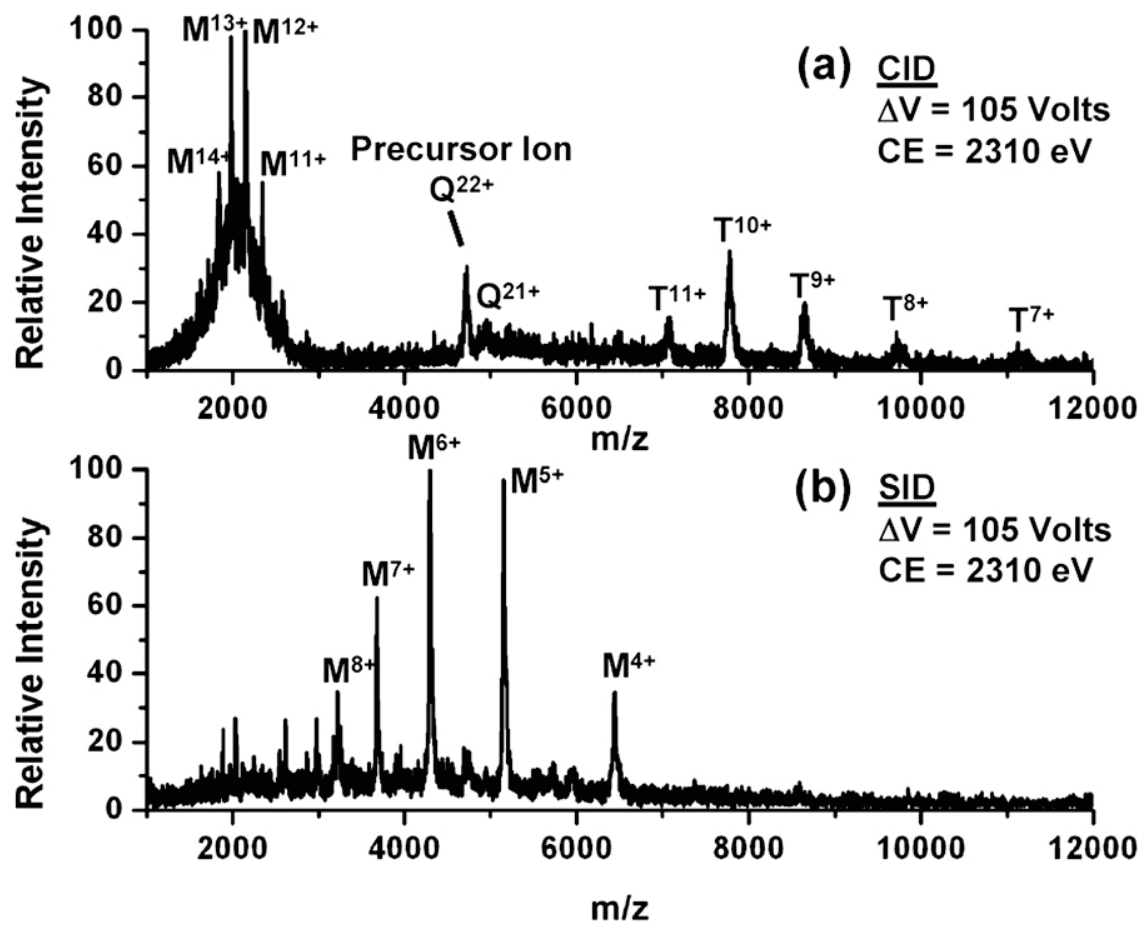

Figure 11. Comparison of CID (a) and SID (b) tandem mass spectra of the $22+$ tetramer $(\mathrm{Q} 22+)$ of concanavalin A from jack bean. The voltage difference and collision energy are defined as in Figure 10. Each protein species is listed as monomers $(\mathrm{M})$, trimers $(\mathrm{T})$, or tetramers $(\mathrm{Q})$ followed by the charge state. 

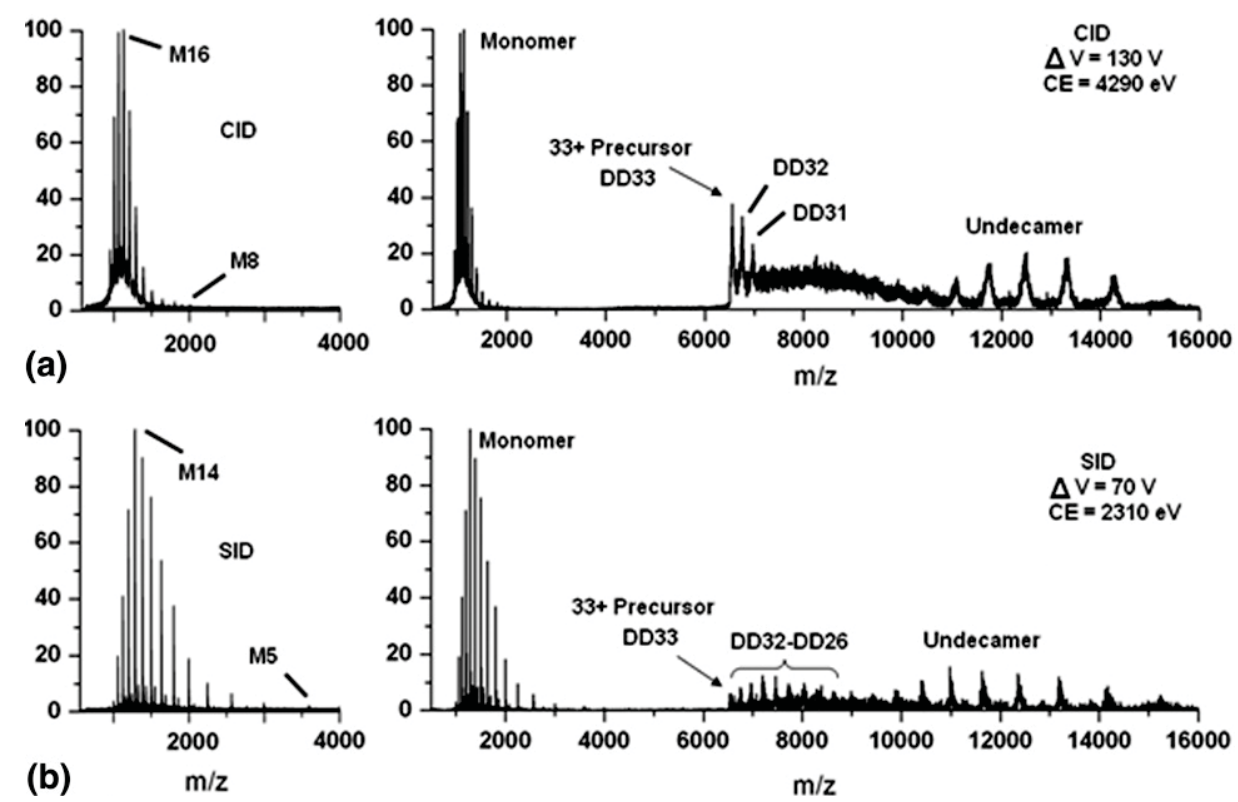

(b)

$\mathrm{m} / \mathbf{z}$

$\mathrm{m} / \mathrm{z}$

Figure 12. SID/CID comparison for the dodecameric protein complex PsHSP18.1, 33+ charge state (DD33). (a) CID at $\Delta \mathrm{V}=130 \mathrm{~V}$, collision energy (CE) $=4290 \mathrm{eV}$. On the left is an enhancement of the low $\mathrm{m} / \mathrm{z}$ region containing monomer fragments centered about the $16+$ charge state (M16). (b) SID at $\Delta \mathrm{V}=70 \mathrm{~V}$, collision energy $(\mathrm{CE})=2310 \mathrm{eV}$. The left-hand side is the enhancement of the monomer region centered about the $14+$ charge state (M14).

distributed over the four dissociating subunits. An indepth study of additional tetrameric and pentameric complexes is currently in preparation and will be presented separately [126].

To address large complexes we have compared the CID and SID of the approximately 200-kDa dodecameric small heat shock protein 18.1 complex (sHSP18.1) from garden pea. This and numerous other sHSPs have been studied quite extensively in the gas phase by Robinson and colleagues. It has been shown that CID induces highly asymmetric mass and charge partitioning upon dissociation of all sHSPs studied thus far, with monomer and $(n-1)$ mer of nearly equal charge being the predominant product ions. Furthermore, evidence of a sequential dissociation pathway, in which monomers continue to be ejected from multimeric product ions at higher collision energies, has also been recently described [120]. Figure 12a shows the CID of sHSP18.1 performed in the University of Arizona QTOF instrument modified with the SID device. In this experiment ions were transmitted through this device without a surface collision and were activated in the collision cell using argon as the target gas. The results are quite typical of what can be found in the literature with a monomer being ejected and removing approximately half of the charge from a $33+$ precursor ion. The SID spectrum of this complex was acquired by deflecting the massselected $33+$ ion into the surface and transmitting the product ions through the collision cell without the presence of a target gas. This spectrum is displayed in Figure $12 \mathrm{~b}$. The first observation that can be made by comparison of the CID and SID data is that the ejected monomer gains less net charge during SID than it does from CID. By CID the most intense monomer charge state was a $16+$ ion, whereas SID yielded a $14+$ ion as its most abundant species. Furthermore, the charge state distribution from SID is slightly broader than that of CID with peaks from $18+$ to $5+$ being observed compared to only $19+$ to $8+$ from CID. Because the higher monomer charge states are the most intense it seems likely that the predominant dissociation pathway remains asymmetric by SID and likely involves some degree of subunit unfolding. However, given that the most abundant ions are less protonated it is feasible that the monomer may be slightly more compact in the transition state. Also, we cannot rule out that partial proton loss to the surface contributes to the observation of lower charge states by SID. Due to the broadness of the charge state distribution observed by SID, it also appears that many more dissociation pathways may also occur, involving varying degrees of subunit unfolding. For instance, the $5+$ ion may result from ejection of a monomer subunit that remains quite compact. At this time it is not entirely clear how to explain the wide distribution of observed charge states. One possibility to consider is that a broad distribution of internal energies and structures exists after the surface collision. Yet another explanation could be that at a given internal energy there exists a number of dissociation pathways that are competitive with the unfolding pathway that is typically dominant (e.g., see Figure 2). Future research will be directed at answering these types of questions. 


\section{Future Directions}

In this short perspective we have presented a wide range of applications, from small molecules to large protein complexes, for which SID has been used over the years. The recent development of an in-line SID device in a QTOF mass spectrometer demonstrates the feasibility of this activation method being implemented in commercial instruments, and is a promising step toward even more widespread use of this technology.

As discussed earlier, an exciting new area where SID is now being applied is to the study of protein complex dissociation pathways and energetics. Given the rich chemistry of large multimeric protein complexes and the fact that SID has only recently been used to study these types of systems, there remains a great deal of work to be done in this area. Our laboratory is currently developing methods involving SID and subsequent gas-phase reactions that are designed to further our understanding of the dissociation pathways of protein complexes. The difference in charge states of monomer product ions formed from either CID or SID has previously been interpreted to indicate a difference in the extent of unfolding in the transition-state structure of the dissociating complex. To study this hypothesis we are in the process of implementing either H/D exchange or ion/ion reactions in the collision cell following the SID device of the QTOF/SID instrument. The reactions with product ions formed either by in-source CID or by SID will be compared. We anticipate that product ions possessing a more unfolded structure will react differently than relatively folded counterparts.

Another promising tool for the study of activated ion structures is ion mobility spectrometry (IMS). Robinson and colleagues [127] have demonstrated the feasibility of such an experiment for a protein complex by studying the gas-phase structure of the TRAP complex, a multimeric assembly known to possess a ring structure in solution. Additionally, Russell and colleagues recently reported an IMS-SID-TOF instrument in which peptide ions were studied [84]. In this instrument the IMS preceded the target surface and product ions were measured by a TOF analyzer. To measure the collision cross sections of SID product ions and activated precursors an instrument would require the IMS region to follow SID. Another intriguing possibility would be to use IMS before the target surface to select specific structures of a given protein complex and investigate how these structures affect dissociation. We believe that the development of a SID-IMS or IMS-SID instrument for protein complexes is feasible and could be an important advance toward the understanding of the structural transitions of complexes and product ions induced by different activation methods. Furthermore, the utility of such an instrument would not be limited to only protein complexes, and could also be used to study the structures of peptide fragment ions following a surface collision.
As mentioned earlier the roles of the surface composition and the projectile ion incidence angle in the efficiency of internal energy deposition remain somewhat ambiguous. Future studies involving a wide range of molecules and surface compositions will be necessary to more precisely define the roles of these experimental variables.

In conclusion, SID has been used to probe the chemistry of a wide variety of molecules and noncovalent assemblies in numerous different instrument configurations. The relative simplicity of ion activation via a short time-frame collision event with a neutral surface has made SID an attractive tool for the study of many types of gas-phase ion chemistries, and is likely to continue providing valuable insights.

\section{Acknowledgments}

The work described was funded by grants to V.H.W. National Science Foundation (NSF) Grant CHE 0416338 for ion-surface reactions and small molecule dissociation, NSF BIO U54 AI065359 for QTOF instrument development, National Institute of General Medical Sciences (NIGMS) Grant R01 GM-051387 for the dissociation of peptides and proteins, and an NIGMS National Research Service Award Fellowship F32 GM-75622 to R.L.B. The authors thank Elizabeth Vierling and coworkers in the Department of Biochemistry and Molecular Biophysics at the University of Arizona for providing the PsHSP 18.1 protein and for general assistance.

\section{References}

1. Cooks, R. G.; Ast, T.; Beynon, J. H. Anomalous Metastable Peaks. Int J. Mass Spectrom. Ion Phys. 1975, 16, 348-352.

2. Cooks, R. G.; Terwilliger, D. T.; Ast, T.; Beynon, J. H.; Keough, T. Surface Modified Mass Spectrometry. J. Am. Chem. Soc. 1975, 97, 1583-1585.

3. Mabud, M. D. A.; Dekrey, M. J.; Cooks, R. G. Surface-Induced Dissociation of Molecular-Ions. Int. J. Mass Spectrom. 1985, 67, 285-294.

4. Laskin, J.; Futrell, J. H. Energy Transfer in Collisions of Peptide Ions with Surfaces. J. Chem. Phys. 2003, 119, 3413-3420.

5. Smith, D. L.; Wysocki, V. H.; Colorado, R.; Shmakova, O. E.; Graupe, M.; Lee, T. R. Low-Energy Ion-Surface Collisions Characterize Alkyland Fluoroalkyl-Terminated Self-Assembled Monolayers on Gold. Langmuir 2002, 18, 3895-3902.

6. Wysocki, V. H.; Kenttamaa, H. I. Collisional Activation of Distonic Radical Cations and Their Conventional Isomers in Quadrupole Tandem Mass Spectrometry. J. Am. Chem. Soc. 1990, 112, 5110-5116.

7. Laskin, J.; Denisov, E.; Futrell, J. Comparative Study of CollisionInduced and Surface-Induced Dissociation. 2. Fragmentation of Small Alanine-Containing Peptides in FT-ICR MS. J. Phys. Chem. B 2001, 105, 1895-1900.

8. Grill, V.; Shen, J.; Evans, C.; Cooks, R. G. Collisions of Ions with Surfaces at Chemically Relevant Energies: Instrumentation and Phenomena. Rev. Sci. Instrum. 2001, 72, 3149-3179.

9. Gologan, B.; Green, J. R.; Alvarez, J.; Laskin, J.; Cooks, R. G. Ion/ Surface Reactions and Ion Soft-Landing. Phys. Chem. Chem. Phys. 2005, 7, 1490-1500.

10. Wysocki, V. H.; Kenttamaa, H. I.; Cooks, R. G. Internal Energy Distributions of Isolated Ions after Activation by Various Methods. Int. J. Mass Spectrom. 1987, 75, 181-208.

11. Cooks, R. G.; Ast, T.; Mabud, M. A. Collisions of Polyatomic Ions with Surfaces. Int. J. Mass Spectrom. 1990, 100, 209-265.

12. DeKrey, M. J.; Kenttamaa, H. I.; Wysocki, V. H.; Cooks, R. G. Energy Deposition in Iron Pentacarbonyl Cation Radical upon Collision with a Metal Surface. Org. Mass Spectrom. 1986, 21, 193-195.

13. Bier, M. E.; Amy, J. W.; Cooks, R. G.; Syka, J. E. P.; Ceja, P.; Stafford, G. A Tandem Quadrupole Mass Spectrometer for the Study of SurfaceInduced Dissociation. Int. J. Mass Spectrom. 1987, 77, 31-47.

14. Vekey, K.; Somogyi, A.; Wysocki, V. H. Internal Energy-Distribution of Benzene Molecular-Ions in Surface-Induced Dissociation. J. Mass Spectrom. 1995, 30, 212-217. 
15. Beck, R. D.; St. John, P.; Homer, M. L.; Whetten, R. L. Impact-Induced Cleaving and Melting of Alkali-Halide Nanocrystals. Science 1991, 253, $879-883$.

16. Beck, R. D.; Warth, C.; May, K.; Kappes, M. M. Surface Impact Induced Shattering of $\mathrm{C}_{60}$. Detection of Small $\mathrm{Cm}$ Fragments by Negative Surface Ionization. Chem. Phys. Lett. 1996, 257, 557-562.

17. Mowrey, R. C.; Brenner, D. W.; Dunlap, B. I.; Mintmire, J. W.; White, C. T. Simulations of Buckminsterfullerene $\left(\mathrm{C}_{60}\right)$ Collisions with a Hydrogen-Terminated Diamond \{111\} Surface. J. Phys. Chem. 1991, 95, 7138-7142.

18. Busmann, H. G.; Lill, T.; Hertel, I. V. Near Specular Reflection of Carbon Sixty-Atom Molecular Ions in Collisions with an HOPG Graphite Surface. Chem. Phys. Lett. 1991, 187, 459-465.

19. Beck, R. D.; Rockenberger, J.; Weis, P.; Kappes, M. M. Fragmentation of C60+ and Higher Fullerenes by Surface Impact. J. Chem. Phys. 1996, 104, 3638-3650.

20. Busmann, H. G.; Lill, T.; Reif, B.; Hertel, I. V.; Maguire, H. G. Energy Partition in Collisions of $\mathrm{C}_{60}{ }^{+}$Ions with Diamond(111) and Graphite(0001) Surfaces. J. Chem. Phys. 1993, 98, 7574-7580.

21. Callahan, J. H.; Somogyi, A.; Wysocki, V. H. Collisions of Fullerene $\mathrm{C} 60+\cdot$ and $\mathrm{C} 602+$ at Fluorinated and Non-Fluorinated Self-Assembled Monolayer Films. Rapid Commun. Mass Spectrom. 1993, 7, 693-699.

22. Beck, R. D.; St. John, P.; Alvarez, M. M.; Diederich, F.; Whetten, R. L. Resilience of All-Carbon Molecules C60, C70, and C84: A SurfaceScattering Time-of-Flight Investigation. J. Phys. Chem. 1991, 95, 84028409

23. Garrison, B. J.; Ryan, K. E.; Russo, M. F. Jr.; Smiley, E. J.; Postawa, Z. Quadratic Friction Model for Cluster Bombardment of Molecular Solids. J. Phys. Chem. C 2007, 111, 10135-10137.

24. Krantzman, K. D.; Kingsbury, D. B.; Garrison, B. J. Cluster Induced Chemistry at Solid Surfaces: Molecular Dynamics Simulations of keV C60 Bombardment of Si. Nucl. Instrum. Methods Phys. Res. B: Beam Interact. Mater. Atoms 2007, 255, 238-241.

25. Delcorte, A.; Garrison, B. J. keV Fullerene Interaction with Hydrocarbon Targets: Projectile Penetration, Damage Creation and Removal. Nucl. Instrum. Methods Phys. Res. B: Beam Interact. Mater. Atoms 2007, 255, 223-228.

26. Russo, M. F. Jr.; Garrison, B.J. Mesoscale Energy Deposition Footprint Model for Kiloelectronvolt Cluster Bombardment of Solids. Anal. Chem. 2006, 78, 7206-7210.

27. Morris, M. R.; Riederer, D. E. Jr.; Winger, B. E.; Cooks, R. G.; Ast, T. Chidsey, C. E. D. Ion/Surface Collisions at Functionalized SelfAssembled Monolayer Surfaces. Int. J. Mass Spectrom. 1992, 122, 181-217.

28. Miller, S. A.; Riederer, D. E. Jr.; Cooks, R. G.; Cho, W. R.; Lee, H. W.; Kang, H. Energy Disposal and Target Effects in Hyperthermal Collisions of Ferrocene Molecular Ions at Surfaces. J. Phys. Chem. 1994, 98, 245-251.

29. Shuler, S. F.; Davis, G. M.; Morris, J. R. Energy Transfer in Rare Gas Collisions with Hydroxyl- and Methyl-Terminated Self-Assembled Monolayers. J. Chem. Phys. 2002, 116, 9147-9150.

30. Day, B. S.; Shuler, S. F.; Ducre, A.; Morris, J. R. The Dynamics of Gas-Surface Energy Exchange in Collisions of Ar Atoms with $\omega$-Functionalized Self-Assembled Monolayers. J. Chem. Phys. 2003, $119,8084-8096$

31. Day, B. S.; Davis, G. M.; Morris, J. R. The Effect of Hydrogen-Bonding and Terminal Group Structure on the Dynamics of Ar Collisions with Self-Assembled Monolayers. Anal. Chim. Acta 2003, 496, 249-258.

32. Day, B. S.; Morris, J. R. Packing Density and Structure Effects on Energy-Transfer Dynamics in Argon Collisions with Organic Monolayers. I. Chem. Phys. 2005, 122, 234714.1-234714.10.

33. Day, B. S.; Morris, J. R.; Troya, D. Classical Trajectory Study of Collisions of Ar with Alkanethiolate Self-Assembled Monolayers: Potential-Energy Surface Effects on Dynamics. J. Chem. Phys. 2005, 122, 214712.1-214712.12.

34. Day, B. S.; Morris, J. R.; Alexander, W. A.; Troya, D. Theoretical Study of the Effect of Surface Density on the Dynamics of Ar + Alkanethiolate Self-Assembled Monolayer Collisions. J. Phys. Chem. A 2006, 110, $1319-1326$.

35. Lohr, J. R.; Day, B. S.; Morris, J. R. Dynamics of $\mathrm{HCl}$ Collisions with Hydroxyl- and Methyl-Terminated Self-Assembled Monolayers. J. Phys. Chem. A 2006, 110, 1645-1649.

36. Mabud, M. A.; Ast, T.; Verma, S.; Jiang, Y. X.; Cooks, R. G. Ion/Surface Interactions as a Tool for Characterizing Isomers: $\left[\mathrm{C}_{2} \mathrm{H}_{4} \mathrm{O}\right]^{+}$Ions. J. Am. Chem. Soc. 1987, 109, 7597-7602.

37. Hayward, M. J.; Mabud, M. A.; Cooks, R. G. Ion/Surface Collisions for Distinction of Isomeric $\left[\mathrm{C}_{6} \mathrm{H}_{6}\right]^{+}$and $\left[\mathrm{C}_{6} \mathrm{H}_{6}\right]^{2+}$ Ions. J. Am. Chem. Soc. 1988, 110, 1343-1346

38. Horning, S. R.; Bier, M. E.; Cooks, R. G.; Brusini, G.; Traldi, P.; Guiotto, A.; Rodighiero, P. Characterization of Isomeric Dimethylfuranocoumarins by Electron Impact Ionization and Surface and Gaseous Collision Activation Mass Spectrometry. Biomed. Environ. Mass Spectrom. 1989, 18, 927-934.

39. Yang, M. C.; Hwang, C. H.; Kang, H. Cs+ Reactive Scattering from a Si(111) Surface Adsorbed with Water. J. Chem. Phys. 1997, 107, 26112618.

40. Kang, H.; Yang, M. C.; Kim, K. D.; Kim, K. Y. Reactive Scattering of $\mathrm{Cs}+$ from Chemisorbed Molecules on a Ni(100) Surface. Secondary Neutral Mass Spectrometry with a Hyperthermal Ion Beam. Int. J. Mass Spectrom. 1998, 174, 143-154.
41. Kim, K. Y.; Shin, T. H.; Han, S. J.; Kang, H. Identification of the Precursor State in the Initial Stages of $\mathrm{Si}(111)-\left(7^{*} 7\right)$ Oxidation. Phys. Rev. Lett. 1999, 82, 1329-1332.

42. Kim, C. M.; Hwang, C.-H.; Lee, C.-W.; Kang, H. Communications: Real-Time Observation of the H/D Exchange Reaction between Ethylene and Hydrogen on Pt(111). Angew. Chem. Int. Ed. Engl. 2002, 41, 146-148.

43. Gu, C.; Wysocki, V. H. Ion-Surface Reactions Involving Isotopically Labeled Langmuir-Blodgett Films. J. Am. Chem. Soc. 1997, 119, 1201012011.

44. Wu, Q.; Hanley, L. Reactive Scattering, Sputtering, and Dissociation of 32-eV Pyridine Ions Colliding with Clean and Pyridine-Covered Silver(111). J. Phys. Chem. 1993, 97, 2677-2685.

45. Wu, Q.; Hanley, L. Effect of Adsorbate Coverage and Ion Beam Exposure Time on Reactive Ion-Surface Collisions: Pyridine Cation $(\mathrm{C} 5 \mathrm{H} 5 \mathrm{~N}+)$ Reactions with Deuterated Pyridine on Silver Surface (C5D5N/Ag(111)). J. Am. Chem. Soc. 1993, 115, 1191-1193.

46. Kane, T. E.; Somogyi, A.; Wysocki, V. H. Reactive Ion-Surface Collisions: Application of Ionized Acetone-d6, DMSO-d6 and Pyridine-d5 as Probes for the Characterization of Self-Assembled Monolayer Films on Gold. Org. Mass Spectrom. 1993, 28, 1665-1673.

47. Angelico, V. J.; Mitchell, S. A.; Wysocki, V. H. Low-Energy Ion-Surface Reactions of Pyrazine with Two Classes of Self-Assembled Monolayers: Influence of Alkyl Chain Orientation. Anal. Chem. 2000, 72, 2603-2608.

48. Barber, M.; Bordoli, R. S.; Sedgwick, R. D.; Tyler, A. N. Fast Atom Bombardment of Solids (FAB) - A New Ion-Source for Mass-Spectrometry. J. Chem. Soc. Chem. Commun. 1981, 7, 325-327.

49. Surman, D. J.; Vickerman, J. C. Fast Atom Bombardment Quadrupole Mass-Spectrometry. J. Chem. Soc. Chem. Commun. 1981, 7, 324-325.

50. Yamashita, M.; Fenn, J. B. Electrospray Ion Source. Another Variation on the Free-Jet Theme. J. Phys. Chem. 1984, 88, 4451-4459.

51. Karas, M.; Bachmann, D.; Bahr, U.; Hillenkamp, F. Matrix-Assisted Ultraviolet-Laser Desorption of Nonvolatile Compounds. Int. J. Mass Spectrom. Ion Process. 1987, 78, 53-68.

52. Kiplinger, J. P.; Bursey, M. M. Collisionally Activated Decomposition of Poly(ethylene glycol)s-An Investigation of High-Mass Ion Abundances in the Collisional Activation Technique with Large Molecules. Org. Mass Spectrom. 1988, 23, 342-349.

53. Alexander, A. J.; Boyd, R. K. Experimental Investigations of Factors Controlling the Collision-Induced Dissociation Spectra of Peptide Ions in a Tandem Hybrid Mass-Spectrometer. 1. Leucine Enkephalin. Int. J. Mass Spectrom. Ion Process. 1989, 90, 211-240.

54. Poulter, L.; Taylor, L. C. E. A Comparison of Low- and High-Energy Collisionally Activated Decomposition MS-MS for Peptide Sequencing. Int. J. Mass Spectrom. Ion Process. 1989, 91, 183-197.

55. Smith, R. D.; Barinaga, C. J.; Udseth, H. R. Tandem Mass-Spectrometry of Highly Charged Cytochrome-C Molecular-Ions Produced by Electrospray Ionization. J. Phys. Chem. 1989, 93, 5019-5022.

56. Williams, E. R.; Henry, K. D.; Mclafferty, F. W.; Shabanowitz, J. Hunt, D. F. Surface-Induced Dissociation of Peptide Ions in FourierTransform Mass-Spectrometry. J. Am. Soc. Mass Spectrom. 1990, 1 413-416.

57. Dongre, A. R.; Somogyi, A.; Wysocki, V. H. Surface-Induced Dissociation: An Effective Tool to Probe Structure, Energetics and Fragmentation Mechanisms of Protonated Peptides. J. Mass Spectrom. 1996, 31 339-350

58. Chorush, R. A.; Little, D. P.; Beu, S. C.; Wood, T. D.; Mclafferty, F. W Surface-Induced Dissociation of Multiply Protonated Proteins. Anal. Chem. 1995, 67, 1042-1046.

59. Hunt, D. F.; Yates, J. R.; Shabanowitz, J.; Winston, S.; Hauer, C. R. Protein Sequencing by Tandem Mass-Spectrometry. Proc. Natl. Acad. Sci. U.S.A. 1986, 83, 6233-6237.

60. Biemann, K. Mass-Spectrometric Methods for Protein Sequencing. Anal. Chem. 1986, 58, 1288A-1300A.

61. Hunt, D. F.; Bone, W. M.; Shabanowitz, J.; Rhodes, J; Ballard, J. M. Sequence-Analysis of Oligopeptides by Secondary Ion-Collision Activated Dissociation Mass-Spectrometry. Anal. Chem. 1981, 53, $1704-$ 1706.

62. Bean, M. F.; Carr, S. A.; Thorne, G. C.; Reilly, M. H.; Gaskell, S. J. Tandem Mass-Spectrometry of Peptides Using Hybrid and 4-Sector Instruments-A Comparative Study. Anal. Chem. 1991, 63, 1473-1481.

63. Tang, X. J.; Thibault, P.; Boyd, R. K. Fragmentation Reactions of Multiply-Protonated Peptides and Implications for Sequencing by Tandem Mass-Spectrometry with Low-Energy Collision-Induced Dissociation. Anal Chem. 1993, 65, 2824-2834.

64. Qin, J.; Chait, B. T. Preferential Fragmentation of Protonated Gas-Phase Peptide Ions Adjacent to Acidic Amino-Acid-Residues. J. Am. Chem. Soc. 1995, 117, 5411-5412.

65. Dongre, A. R.; Jones, J. L.; Somogyi, A.; Wysocki, V. H. Influence of Peptide Composition, Gas-Phase Basicity, and Chemical Modification on Fragmentation Efficiency: Evidence for the Mobile Proton Model. J. Am. Chem. Soc. 1996, 118, 8365-8374.

66. Summerfield, S. G.; Whiting, A.; Gaskell, S. J. Intra-ionic Interactions in Electrosprayed Peptide Ions. Int. J. Mass Spectrom. Ion Process. 1997, $162,149-161$.

67. Tsaprailis, G.; Nair, H.; Somogyi, A.; Wysocki, V. H.; Zhong, W.; Futrell, J. H.; Summerfield, S. G.; Gaskell, S. J. Influence of Secondary Structure on the Fragmentation of Protonated Peptides. J. Am. Chem. Soc. 1999, 121, 5142-5154. 
68. Huang, Y. Y.; Triscari, J. M.; Pasa-Tolic, L.; Anderson, G. A.; Lipton, M. S.; Smith, R. D.; Wysocki, V. H. Dissociation Behavior of Doublycharged Tryptic Peptides: Correlation of Gas-Phase Cleavage Abundance with Ramachandran Plots. J. Am. Chem. Soc. 2004, 126, 30343035

69. Tsaprailis, G.; Nair, H.; Zhong, W.; Kuppannan, K.; Futrell, J. H.; Wysocki, V. H. A Mechanistic Investigation of the Enhanced Cleavage at Histidine in the Gas-Phase Dissociation of Protonated Peptides. Anal. Chem. 2004, 76, 2083-2094.

70. Huang, Y. Y.; Triscari, J. M.; Tseng, G. C.; Pasa-Tolic, L.; Lipton, M. S.; Smith, R. D.; Wysocki, V. H. Statistical Characterization of the Charge State and Residue Dependence of Low-Energy CID Peptide Dissociation Patterns. Anal. Chem. 2005, 77, 5800-5813.

71. Gorman, G. S.; Speir, J. P.; Turner, C. A.; Amster, I. J. Proton Affinities of the 20 Common Alpha-Amino-Acids. J. Am. Chem. Soc. 1992, 114, 3986-3988.

72. Wu, Z. C.; Fenselau, C. Proton Affinity of Arginine Measured by the Kinetic Approach. Rapid Commun. Mass Spectrom. 1992, 6, 403-405.

73. Wu, Z. C.; Fenselau, C. Gas-Phase Basicities and Proton Affinities of Lysine and Histidine Measured from the Dissociation of Proton-Bound Dimers. Rapid Commun. Mass Spectrom. 1994, 8, 777-780.

74. Lias, S. G.; Liebmann, L. F.; Levine, R. D. J. Phys. Chem. Ref. Data 1984, 13, 695-808.

75. Biemann, K. Sequencing of Peptides by Tandem Mass Spectrometry and High-Energy Collision-Induced Dissociation. Methods Enzymol. $1990,193,455-479$.

76. Alexander, A. J.; Thibault, P.; Boyd, R. K.; Curtis, J. M.; Rinehart, K. L. Collision-Induced Dissociation of Peptide Ions. 3. Comparison of Results Obtained Using Sector-Quadrupole Hybrids with Those from Tandem Double-Focusing Instruments. Int. J. Mass Spectrom. Ion Process. 1990, 98, 107-134.

77. Jones, J. L.; Dongre, A. R.; Somogyi, A.; Wysocki, V. H. Sequence Dependence of Peptide Fragmentation Efficiency Curves Determined by Electrospray-Ionization Surface-Induced Dissociation MassSpectrometry. J. Am. Chem. Soc. 1994, 116, 8368-8369.

78. Cox, K. A.; Gaskell, S. J.; Morris, M.; Whiting, A. Role of the Site of Protonation in the Low-Energy Decompositions of Gas-Phase Peptide Ions. J. Am. Soc. Mass Spectrom. 1996, 7, 522-531.

79. Gu, C.; Tsaprailis, G.; Breci, L.; Wysocki, V. H. Selective Gas-Phase Cleavage at the Peptide Bond C-Terminal to Aspartic Acid in FixedCharge Derivatives of Asp-Containing Peptides. Anal. Chem. 2000, 72, $5804-5813$

80. Wysocki, V. H.; Tsaprailis, G.; Smith, L. L.; Breci, L. A. Special Feature: Commentary-Mobile and Localized Protons: A Framework for Understanding Peptide Dissociation. J. Mass Spectrom. 2000, 35, 13991406 .

81. Kapp, E. A.; Schuetz, F.; Reid, G. E.; Eddes, J. S.; Moritz, R. L.; O'Hair, R. A. J.; Speed, T. P.; Simpson, R. J. Mining a Tandem Mass Spectrometry Database to Determine the Trends and Global Factors Influencing Peptide Fragmentation. Anal. Chem. 2003, 75, 6251-6264.

82. Stone, E.; Gillig, K. J.; Ruotolo, B.; Fuhrer, K.; Gonin, M.; Schultz, A. Russell, D. H. Surface-Induced Dissociation on a MALDI-Ion MobilityOrthogonal Time-of-Flight Mass Spectrometer: Sequencing Peptides from an "In-Solution" Protein Digest. Anal. Chem. 2001, 73, 2233-2238.

83. Stone, E. G.; Gillig, K. J.; Ruotolo, B. T.; Russell, D. H. Optimization of a Matrix-Assisted Laser Desorption Ionization-Ion Mobility-SurfaceInduced Dissociation-Orthogonal-Time-of-Flight Mass Spectrometer: Simultaneous Acquisition of Multiple Correlated MS1 and MS2 Spectra. Int. J. Mass Spectrom. 2001, 212, 519-533.

84. Sun, W.; May, J. C.; Russell, D. H. A Novel Surface-Induced Dissociation Instrument for Ion Mobility-Time-of-Flight Mass Spectrometry. Int. J. Mass Spectrom. 2007, 259, 79-86.

85. Laskin, J.; Denisov, E. V.; Shukla, A. K.; Barlow, S. E.; Futrell, J. H. Surface-Induced Dissociation in a Fourier Transform Ion Cyclotron Resonance Mass Spectrometer: Instrument Design and Evaluation. Anal. Chem. 2002, 74, 3255-3261.

86. Schlosser, A.; Lehmann, W. D. Patchwork Peptide Sequencing: Extraction of Sequence Information from Accurate Mass Data of Peptide Tandem Mass Spectra Recorded at High Resolution. Proteomics 2002, 2, 524-533.

87. Fernandez, F. M.; Wysocki, V. H.; Futrell, J. H.; Laskin, J. Protein Identification via Surface-Induced Dissociation in an FT-ICR Mass Spectrometer and a Patchwork Sequencing Approach. J. Am. Soc. Mass Spectrom. 2006, 17, 700-709.

88. Shukla, A. K.; Futrell, J. H. Tandem Mass Spectrometry: Dissociation of Ions by Collisional Activation. I. Mass Spectrom. 2000, 35, 1069-1090.

89. Williams, E. R.; Fang, L. L.; Zare, R. N. Surface Induced Dissociation for Tandem Time-of-Flight Mass-Spectrometry. Int. J. Mass Spectrom. Ion Process. 1993, 123, 233-241.

90. Vekey, K.; Somogyi, A.; Wysocki, V. H. Average Activation Energies of Low-Energy Fragmentation Processes of Protonated Peptides Determined by a New Approach. Rapid Commun. Mass Spectrom. 1996, 10, 911-918.

91. Laskin, J.; Denisov, E.; Futrell, J. A Comparative Study of CollisionInduced and Surface-Induced Dissociation. 1. Fragmentation of Protonated Dialanine. J. Am. Chem. Soc. 2000, 122, 9703-9714.

92. Laskin, J.; Futrell, J. H. Collisional Activation of Peptide Ions in FT-ICR Mass Spectrometry. Mass Spectrom. Rev. 2003, 22, 158-181.

93. Laskin, J.; Futrell, J. Internal Energy Distributions Resulting from Sustained Off-Resonance Excitation in Fourier Transform Ion Cyclo- tron Resonance Mass Spectrometry. II. Fragmentation of the 1-Bromonaphthalene Radical Cation. J. Phys. Chem. A 2000, 104 5484-5494.

94. Laskin, J.; Byrd, M.; Futrell, J. Internal Energy Distributions Resulting from Sustained Off-Resonance Excitation in FTMS. I. Fragmentation of the Bromobenzene Radical Cation. Int. J. Mass Spectrom. 2000, 196, 285-302.

95. Dekrey, M. J.; Kenttamaa, H. I.; Wysocki, V. H.; Cooks, R. G. Energy Deposition in $[\mathrm{Fe}(\mathrm{Co}) 5]+$ Upon Collision with a Metal-Surface. Org. Mass Spectrom. 1986, 21, 193-195.

96. Wysocki, V. H.; Ding, J. M.; Jones, J. L.; Callahan, J. H.; King, F. L. Surface-Induced Dissociation in Tandem Quadrupole Mass Spectrometers-A Comparison of 3 Designs. J. Am. Soc. Mass Spectrom. 1992, 3, 27-32

97. Laskin, J.; Futrell, J. H. Collisional Activation of Peptide Ions in FT-ICR Mass Spectrometry. Rapid Commun. Mass Spectrom. 2003, 17, 2694.

98. Meroueh, O.; Hase, W. L. Dynamics of Energy Transfer in PeptideSurface Collisions. J. Am. Chem. Soc. 2002, 124, 1524-1531.

99. Meroueh, O.; Wang, Y. F.; Hase, W. L. Direct Dynamics Simulations of Collision- and Surface-Induced Dissociation of N-Protonated Glycine Shattering Fragmentation. J. Phys. Chem. A 2002, 106, 9983-9992.

100. Song, K.; Meroueh, O.; Hase, W. L. Dynamics of $\mathrm{Cr}(\mathrm{CO})_{6}{ }^{+}$Collisions with Hydrogenated Surfaces. J. Chem. Phys. 2003, 118, 2893-2902.

101. Wang, Y. F.; Hase, W. L. Direct Dynamics Study of N-Protonated Diglycine Surface-Induced Dissociation. Influence of Collision Energy. J. Am. Soc. Mass Spectrom. 2003, 14, 1402-1412.

102. Wang, J. P.; Meroueh, S. O.; Wang, Y. F.; Hase, W. L. Efficiency of Energy Transfer in Protonated Diglycine and Dialanine SID-Effects of Collision Angle, Peptide Ion Size, and Intramolecular Potential. Int. J. Mass Spectrom. 2003, 230, 57-64.

103. Laskin, J.; Bailey, T. H.; Futrell, J. H. Shattering of Peptide Ions on Self-Assembled Monolayer Surfaces. J. Am. Chem. Soc. 2003, 125 $1625-1632$

104. Laskin, J.; Bailey, T. H.; Futrell, J. H. Fragmentation Energetics for Angiotensin II and Its Analogs from Time- and Energy-Resolved Surface-Induced Dissociation Studies. Int. J. Mass Spectrom. 2004, 234, 89-99.

105. Laskin, J.; Bailey, T. H.; Futrell, J. H. Mechanisms of Peptide Fragmentation from Time- and Energy-Resolved Surface-Induced Dissociation Studies: Dissociation of Angiotensin Analogs. Int. J. Mass Spectrom. 2006, 249, 462-472.

106. Laskin, J. Energetics and Dynamics of Fragmentation of Protonated Leucine Enkephalin from Time- and Energy-Resolved Surface-Induced Dissociation Studies. J. Phys. Chem. A 2006, 110, 8554-8562.

107. Park, K.; Song, K.; Hase, W. L. An Ab Initio Direct Dynamics Simulation of Protonated Glycine Surface-Induced Dissociation. Int. J. Mass Spectrom. 2007, 265, 326-336.

108. Schultz, D. G.; Lim, H.; Garbis, S.; Hanley, L. Energy Partitioning in the Surface-Induced Dissociation of Linear and Cyclic Protonated Peptides at an Organic Surface. J. Mass Spectrom. 1999, 34, 217-225.

109. Schultz, D. G.; Hanley, L. Shattering of SiMe3+ during SurfaceInduced Dissociation. J. Chem. Phys. 1998, 109, 10976-10983.

110. Gamage, C. M.; Fernandez, F. M.; Kuppannan, K.; Wysocki, V. H. Submicrosecond Surface-Induced Dissociation of Peptide Ions in a MALDI TOF MS. Anal. Chem. 2004, 76, 5080-5091.

111. Benesch, J.; Robinson, C. Mass Spectrometry of Macromolecular Assemblies: Preservation and Dissociation. Curr. Opin. Struct. Biol. 2006, 16, 245-251.

112. Felitsyn, N.; Kitova, E. N.; Klassen, J. S. Thermal Decomposition of a Gaseous Multiprotein Complex Studied by Blackbody Infrared Radiative Dissociation. Investigating the Origin of the Asymmetric Dissociation Behavior. Anal. Chem. 2001, 73, 4647-4661.

113. Hanson, C. L.; Fucini, P.; Ilag, L. L.; Nierhause, K. H.; Robinson, C. V Dissociation of Intact Escherichia coli Ribosomes in a Mass Spectrometer. J. Biol. Chem. 2003, 278, 1259-1267.

114. Jurchen, J. C.; Garcia, D. E.; Williams, E. R. Further Studies on the Origins of Asymmetric Charge Partitioning in Protein Homodimers. J. Am. Soc. Mass. Spectrom. 2004, 15, 1408-1415.

115. McCammon, M. G.; Hernandez, H.; Sobott, F.; Robinson, C. V. Tandem Mass Spectrometry Defines the Stoichiometry and Quaternary Structural Arrangement of Tryptophan Molecules in the Multiprotein Complex TRAP. J. Am. Chem. Soc. 2004, 126, 5950-5951.

116. Rostom, A. A.; Fucini, P.; Benjamin, D. R.; Juenemann, R.; Nierhaus, K. H.; Hartl, F. U.; Dobson, C. M.; Robinson, C. V. Detection and Selective Dissociation of Intact Ribosomes in a Mass Spectrometer. Proc. Natl. Acad. Sci. U.S.A. 2000, 97, 5185-5190.

117. Sobott, F.; Robinson, C. V. Protein Complexes Gain Momentum. Curr. Opin. Struct. Biol. 2002, 12, 729-734

118. Sobott, F.; Hernandez, H.; McCammon, M. G.; Tito, M. A.; Robinson, C. V. A Tandem Mass Spectrometer for Improved Transmission and Analysis of Large Macromolecular Assemblies. Anal. Chem. 2002, 74, 1402-1407.

119. Sobott, F.; McCammon, M. G.; Robinson, C. V. Gas-Phase Dissociation Pathways of a Tetrameric Protein Complex. Int. J. Mass Spectrom. 2003, 230, 193-200.

120. Benesch, J. L. P.; Aquilina, J. A.; Ruotolo, B. T.; Sobott, F.; Robinson, C. V. Tandem Mass Spectrometry Reveals the Quaternary Organization of Macromolecular Assemblies. Chem. Biol. 2006, 13, 597-605.

121. McLuckey, S. A.; Goeringer, D. E. Slow Heating Methods in Tandem Mass Spectrometry. J. Mass Spectrom. 1997, 32, 461-474. 
122. Versluis, C.; van der Staaij, A.; Stokvis, E.; Heck, A. J. R.; de Craene, B. Metastable Ion Formation and Disparate Charge Separation in the Gas-Phase Dissection of Protein Assemblies Studied by Orthogonal Time-of-Flight Mass Spectrometry. J. Am. Soc. Mass Spectrom. 2001, 12, 329-336.

123. Galhena, A. S.; Dagan, S.; Wysocki, V. H. Surface-Induced Dissociation of Peptides and Protein Complexes in a Quadrupole/Time-of-Flight Mass Spectrometer. Anal. Chem. (in press)

124. Jones, C. M.; Beardsley, R. L.; Galhena, A. S.; Dagan, S.; Wysocki, V. H. Symmetrical Gas-Phase Dissociation of Noncovalent Protein
Complexes via Surface Collisions. J. Am. Chem. Soc. 2006, 128, 15044-15045.

125. Light-Wahl, K. J.; Schwartz, B. L.; Smith, R. D. Observation of the Noncovalent Quaternary Associations of Proteins by Electrospray Ionization Mass Spectrometry. J. Am. Chem. Soc. 1994, 116, 5271-5278.

126. Beardsley, R. L.; Jones, C. M.; Galhena, A. S.; Wysocki, V. H., unpublished data.

127. Ruotolo, B. T.; Giles, K.; Campuzano, I.; Sandercock, A. M.; Bateman, R. H.; Robinson, C. V. Evidence for Macromolecular Protein Rings in the Absence of Bulk Water. Science 2005, 310, 1658-1661. 